REVISTA DE DERECHO UNED, núm. 6, 2010

\title{
LOS CONSUMIDORES ANTE LOS CONTRATOS A DISTANCIA

\author{
Estudio del ordenamiento español a la luz de la \\ jurisprudencia del TJUE: Asuntos easyCar \\ y Handelsgesellschaft Heinrich Heine GmbH
}

\author{
Alicia Arroyo Aparicio \\ Profesora Titular de Derecho Mercantil. UNED \\ "Consumers, by definition, include us all» Kennedy, \\ 15 March 1962, Declaration to the US Congress*
}

Resumen: La normativa española que rige la contratación a distancia está prevista por el texto refundido de la Ley General para la protección de los Consumidores y Usuarios, que incorpora la transposición de la Directiva 97/7/CE, referida a los contratos celebrados por consumidores a través de un sistema que no requiere la presencia física simultánea de las partes contratantes. Los consumidores quedan protegidos por normas que disciplinan: el derecho de desistimiento atribuido en determinadas circunstancias, el suministro de la información por escrito o en soporte duradero; el reembolso de los pagos anticipados o el uso fraudulento de tarjetas de crédito; y la conside-

\footnotetext{
* Desde que el Presidente Kennedy pronunciara esta célebre frase hasta hoy la normativa de protección de los consumidores ha experimentado importantes cambios. En esta frase puede verse la equiparación de consumidor con el ciudadano, distinta de la noción concreta que sirve para atribuir derechos al consumidor en cada caso. Este trabajo, que considera al consumidor ante los contratos a distancia con referencia a los más recientes pronunciamientos del TJUE, se enmarca en el Proyecto del MEC SEJ2007-67381/JURI.
} 
ración de los servicios no solicitados como una práctica prohibida. Las normas de la Directiva 97/7/CE, por lo que respecta a la armonización europea, han requerido de interpretación jurisprudencial por parte del TJUE, que se ha pronunciado sobre el derecho de desistimiento, el más relevante de los atribuidos al consumidor.

Palabras clave: contratos a distancia; protección de los consumidores y usuarios; derecho de desistimiento; jurisprudencia comunitaria; interpretación de Directivas.

\begin{abstract}
Spanish legislation establishes principles relating to contracts which may be provided at a distance under Consumer Protection Act (texto refundido de la LGDCU) that include implementation of the Directive 97/7/EC. It covers contracts that are negociated by any means without the simultaneous physical presence of the parties to the contract. Consumer protection is first supported by the unilateral right of withdrawal in specific circumstances. Consumers are further protected by the supply of information in writing or on another durable medium; the entitlement to a reimbursement of the sums paid and the protection in the event of fraudulent use of his/her credit card. The unsolicited supply of services is also considered as a prohibited commercial practice. The provisions of the Directive 97/7/EC of the European Parliament and of the Council of 20 May 1997 on the protection of consumers in respect of distance contracts - as far as European harmonisation is concerned- require the interpretation by the Tribunal of Justice, that mainly analyzed the case of withdrawal by the consumer.
\end{abstract}

Sumario: I. Consideraciones previas.-II. Contratos celebrados a distancia con consumidores en el texto refundido de la LGDCU.-1. Aspectos generales.-2. Imperatividad de las normas.-3. Integración con el conjunto del ordenamiento jurídico.-4. Contratos electrónicos.-5. Ámbito subjetivo de aplicación de la regulación sobre contratos a distancia.-5.1. Delimitación legal.-5.2. El sujeto protegido: el consumidor.-5.3. El empresario y profesional.-6. Ámbito objetivo de aplicación de la regulación sobre contratos a distancia.-6.1. Requisitos delimitadores de los contratos a distancia.-6.2. Exclusiones del ámbito objetivo de aplicación de la regulación sobre contratos a distancia.-7. Especialidades en la formación del contrato.-7.1 Aplicación del Derecho codificado y de la LSSI.-7.2. Información previa exigible.-7.3. Manifestación del consentimiento del consumidor.-7.4. Suministro de bienes y servicios no solicitados.-8. Especialidades en la ejecución del contrato.-8.1. Constancia escrita o en soporte duradero de la información.-8.2. Entrega y prestación del servicio.-8.3. 
Pago mediante tarjeta.-9. Derecho de desistimiento.-9.1. Reconocimiento legal del «derecho de desistimiento» para los contratos a distancia. Naturaleza.-9.2. Régimen jurídico.-III. Contratos a distancia en la jurisprudencia del TJUE (Asuntos easyCar y Handelsgesellschaft Heinrich Heine).-1. Exclusión del derecho de desistimiento en los contratos a distancia de alquiler de coches, en tanto que son considerados como "contratos de suministro de servicios de transporte»: el Asunto "easyCar».-A) Antecedentes: el litigio y la cuestión prejudicial.-B) La Sentencia «easyCar» de 10 de marzo de 2005.-C) Conclusiones.-2. Desistimiento de contrato por parte del consumidor y el alcance de la prohibición de repercutir sobre él de los gastos de envío: el Asunto Heinrich Heine.-A) Antecedentes: el litigio y la cuestión prejudicial.-B) La Sentencia de 15 de abril de 2010.-C) Conclusiones.-3. El derecho de desistimiento como objeto de debate.

\section{CONSIDERACIONES PREVIAS}

La problemática que presentan los contratos a distancia está vinculada al modo de contratación, realizado entre un empresario y un consumidor en el marco de un sistema organizado por el primero para ofrecer a distancia sus bienes o servicios valiéndose a tal fin de la utilización exclusiva de técnicas de comunicación. Así, los problemas básicos a los que el consumidor se enfrenta en este tipo de contratación cuando contrae un compromiso - que podría denominarse «a ciegas»- son: (i) que no tiene posibilidad de verificar la identidad de la otra parte contratante; (ii) que no puede comprobar de manera directa y personal las características del objeto sobre el que contrata; y (iii) que no queda claramente determinado en qué momento surgen las obligaciones para las partes.

Esta modalidad de contratación con consumidores recibió hace ya más de una década regulación específica a nivel comunitario mediante la Directiva 97/7/CE ${ }^{1}$. A nivel interno, la regulación ha pasado por vicisitudes importantes: en un primer momento, se hallaba contenida en la Ley 7/1996, de 15 de enero, de ordenación del comercio minorista (LOCM), habiendo sido modificada esa regulación originaria de 1996 por la Ley 47/2002, de 19 de diciembre, para una total

1 Directiva del Parlamento Europeo y del Consejo, de 20 de mayo de 1997, relativa a la protección de los consumidores en materia de contratos a distancia. Vid. también la Comunicación de la Comisión sobre la aplicación de la Directiva 97/7/CE, de 21 septiembre 2006 - COM (2006) 514 final. 
transposición del texto comunitario al ordenamiento español ${ }^{2}$. Ahora bien, con la entrada en vigor del Real Decreto Legislativo 1/2007, de 16 de noviembre, por el que se aprobó el texto refundido de la Ley General para la Defensa de los Consumidores y Usuarios y otras leyes complementarias (en adelante LGDCU), la referida regulación contenida en la LOCM se duplica de forma peculiar. Así, por una parte, permanece en la LOCM la misma regulación, aunque con algunas normas derogadas, con el ámbito subjetivo modificado y el carácter de las normas también. Como resultado de estos cambios queda en la LOCM una regulación dispositiva, aplicable sólo al intercambio de bienes - no a los servicios cuya regulación en la LOCM se deroga-y relativa a las "relaciones empresariales», es decir, entre empresarios (según el tenor literal del preámbulo del Real Decreto legislativo 1/2007). Por otra parte, el régimen completo de los contratos a distancia celebrados con consumidores pasa a hallarse en el texto refundido de la LGDCU ${ }^{3}$.

Esto es, a partir de la nueva LGDCU, la normativa sobre contratos a distancia queda recogida en dos normas: la relativa a los contratos con consumidores, que se integra en el texto refundido, y la relativa a las «relaciones empresariales» que permanece a la vez vigente - aunque con cambios- en la LOCM. En el presente trabajo se analiza de forma destacada la regulación contenida en la LGDCU, esto es, los contratos a distancia con consumidores (infra II), así como dos importantes Sentencias del TJUE recaídas sobre la Directiva 97/7/CE, que aportan luz sobre las normas nacionales y merecen un análisis aparte (infra III).

Reténgase, en todo caso, que la regulación que permanece en la LOCM es similar a la que se halla hoy en la LGDCU con algunas peculiaridades llamativas que, aún no recibiendo aquí un detenimiento mayor, sí que han de apuntarse al menos. Pues bien, el RDLeg 1/2007 afecta, como se ha anticipado, a la regulación contenida en la

2 Transposición tardía, tal y como se declaró en la STJCE de 28 noviembre 2002 ([TJCE 2002, 355]; Comisión c. España, As. C-414/2001).

3 Sobre la regulación española, extensamente: ARROYO APARICIO, A., Los contratos a distancia en la Ley de Ordenación del Comercio Minorista (Según la Ley 47/2002, de 19 diciembre 2002, de reforma de la Ley de Ordenación del Comercio Minorista), Aranzadi, 2003. Nótese que el Real Decreto Legislativo 1/2007 incorpora a la LGDCU la regulación de la LOCM, pues se trata en esencia de una refundición y no de una modificación de la normativa española. Sobre la regulación ya incorporada al texto refundido: ARROYO APARICIO, A., "Contratos a distancia celebrados con consumidores según la Ley General para la Defensa de Consumidores y Usuarios (Texto Refundido por el Real Decreto Legislativo 1/2007)», Contratos Mercantiles, Tomo I, (Bercovitz, A. Dir.), Aranzadi, 2009, pp. 168 a 223. 
LOCM y, según se expresa en el apartado II de su preámbulo, lo hace del siguiente modo: se incorporan al texto refundido las disposiciones destinadas a regular las relaciones jurídicas con los consumidores en los contratos a distancia de bienes y servicios contenidas en la LOCM; pero "como consecuencia de esta refundición», la regulación sobre contratos a distancia contenida en la LOCM «queda vigente para la regulación de las relaciones empresariales». Se aprecia que no se justifica - ni se entiende fácilmente- la duplicación o coexistencia producida, que se sostiene como mera "consecuencia» de la refundición. Cabe preguntarse si esa consecuencia era necesaria, sobre todo en tanto que difiere de lo que ha ocurrido con el resto de normas sobre consumidores, que al pasar al texto refundido han sido lógicamente derogadas. Es cierto que un sector doctrinal mantuvo que la regulación de la LOCM - aún correspondiendo a la transposición de una Directiva comunitaria de protección de los consumidores y conteniendo normas típicas exclusivamente de esta protección- se aplicaba tanto a consumidores como a no consumidores; y con base en esta consideración podría entonces sustentarse la duplicación producida —o derogación parcial—. Pero también es cierto que aquélla interpretación no fue pacífica, sino siempre discutida $^{4}$.

De la regulación contenida en la LOCM resulta criticable que se hayan mantenido en dicha Ley unas normas relativas a las «relaciones empresariales», que no pertenecen en sentido estricto al "comercio minorista» ni, por tanto, se adecuan totalmente al ámbito de aplicación delimitado por el artículo $1^{\circ}$ de la LOCM. Pero, sobre todo, ha de destacarse que el legislador no ha resuelto este desajuste con la disposición derogatoria única, apartado $1^{\circ}$, del texto refundido de la LGDCU, que afronta únicamente dos de los aspectos antes referidos: (i) el primero, el carácter de las normas que se mantienen en la LOCM - que pasan a ser dispositivas por derogación del artículo 48 LOCM-; y (ii) el segundo, la supresión de la regulación para servicios a distancia por derogación de la disposición adicional primera de la LOCM. La disposición derogatoria ha suprimido igualmente el artículo 65.1 LOCM relativo a las sanciones administrativas correspondientes a la infracción de las normas sobre contratos a distancia. Obsérvese, además, que en numerosas ocasiones la LOCM emplea en la normativa que queda vigente el término de «consumidor» para

\footnotetext{
${ }^{4}$ ARROYO APARICIO, A., Los contratos a distancia, op. cit., pp. 124 a 127, donde se mantiene, rebatiendo las tesis contrarias, que la regulación de la LOCM se aplicaba sólo a los contratos celebrados entre un empresario y un consumidor.
} 
una regulación referida ya únicamente a relaciones «empresariales», esto es, celebradas entre empresarios y no con consumidores ${ }^{5}$.

Quedan en la LOCM, por tanto, normas dispositivas, aplicables a las «relaciones empresariales» —obsérvese que la delimitación del ámbito de estas normas se halla ahora en el preámbulo del RDLeg. 1/2007_, que consistan en "ventas a distancia» — y no en prestación de servicios-, en las que se exige que el vendedor informe de determinados extremos (arts. 39 y 40 LOCM). También se exige que el comprador consienta de manera expresa (art. 41 LOCM) y se prohíben los «envíos no solicitados» (art. 42). La normativa impone así mismo plazos de entrega para el caso de que no se haya pactado otro (art. 43 LOCM), al igual que contiene previsiones para el uso fraudulento de tarjetas de pago (art. 46 LOCM). El vendedor habrá de facilitar al comprador información escrita o en soporte duradero, contando éste además con un derecho de desistimiento (art. 44 y 45).

En suma, cabe dudar de si el mantenimiento de las normas de la LOCM resulta apropiado y acorde con la habilitación en la que se basa la elaboración del texto refundido.

\section{CONTRATOS CELEBRADOS A DISTANCIA CON CONSUMIDORES EN EL TEXTO REFUNDIDO DE LA LGDCU}

\section{Aspectos generales}

En la medida en que el texto refundido, Real Decreto Legislativo 1/2007 persigue evitar repeticiones innecesarias al integrar diferentes textos legales ${ }^{6}$, resulta necesario estar al contenido específico referido

5 SÁNCHEZ GÓMEZ, A., en Comentario del Texto Refundido de la Ley General para la Defensa de los Consumidores y Usuarios, (R. Bercovitz, Coord.), Aranzadi, 2009, sub art. 92, p. 1183, alude al posible mantenimiento de estas normas como una suerte de «Derecho general aplicable a los contratos a distancia entre un empresario y un destinatario final». Si bien no cabe olvidar que el preámbulo del R. D. Lgtvo. especifica expresamente que las normas que permanecen en la LOCM quedan vigentes «para la regulación de las relaciones empresariales».

6 El texto refundido se aprueba en cumplimiento de la delegación legislativa recogida en la Ley 44/2006, de mejora de la protección de los consumidores y usuarios. En dicho texto han quedado refundidos, además de la Ley General para la Defensa de los Consumidores y Usuarios, la Ley sobre contratos celebrados fuera de los establecimientos mercantiles, la Ley de responsabilidad civil por los daños causados por productos defectuosos, la Ley reguladora de los viajes combinados, la Ley de garantías en la venta de bienes de consumo, así como la regulación de los contratos a distancia con consumidores contenida anteriormente en la LOCM, con las matizaciones expresadas anteriormente (supra I). 
al contrato a distancia, así como a las normas generales que resulten de aplicación. En concreto, deberán considerarse los artículos 92 a 106 LGDCU, destinados a los contratos a distancia con consumidores (quince artículos en total), y las normas referidas a: el concepto de consumidor (art. 3 LGDCU), el carácter imperativo de la regulación (art. 10 LGDCU), el derecho de desistimiento (arts. 68 y ss. LGD$\mathrm{CU}$ ), las infracciones y sanciones correspondientes (arts. 46 y ss. LGDCU) y las acciones que procedan, tanto judiciales (arts. 53 y ss. LGDCU, referidas a las acciones de cesación) como extrajudiciales (arts. 57 y ss. LGDCU, referidas al arbitraje de consumo).

En líneas generales, se trata de un contrato celebrado sin la presencia física de las partes contratantes, con el empleo exclusivo de técnicas de comunicación a distancia, en el marco de un sistema organizado por el empresario (art. 92 LGDCU). En relación con dicho contrato pesa sobre el empresario el deber de informar al consumidor de determinados extremos (arts. 97 y 98 LGDCU), es preciso que el consumidor preste su consentimiento de manera expresa (art. 99 LGDCU) y se prohíbe - en todo caso- la práctica denominada «envíos no solicitados» (art. 100 LGDCU). En la regulación se dan además otras particularidades en cuanto a la ejecución del contrato: se trata de la imposición al empresario de un plazo de entrega para el caso en que no se haya pactado otro diferente (art. 103 LGDCU), de determinadas previsiones relativas al uso fraudulento de las tarjetas de pago (art. 106 LGDCU) y de la información por escrito o en soporte duradero que ha de entregarse al consumidor a la ejecución del contrato (art. 98). Pero, sin duda, el principal derecho atribuido al consumidor consiste en el de desistimiento - ejercitable sin justificación de causa - y que se regula con carácter general en los artículos 68 y siguientes de la LGDCU con las peculiaridades propias previstas para los contratos a distancia en los artículos 101 y 102 LGDCU.

\section{Imperatividad de las normas}

Otro de los aspectos que han de ser destacados consiste en el carácter imperativo de la regulación en virtud del artículo 10 LGDCU que dispone la irrenunciabilidad de los derechos reconocidos al consumidor y usuario, de manera que la renuncia previa es nula. Con anterioridad al texto refundido, el carácter imperativo de la regulación sobre contratos a distancia venía dispuesto por el antiguo artículo 48.1 de la LOCM, ya derogado, pero hoy se recoge en las disposicio- 
nes generales, aplicables también a los contratos a distancia. En todo caso, supone que cualquier contenido contractual menos beneficioso para el consumidor que el establecido por la Ley no es válido: es una imperatividad de mínimos (son nulas las cláusulas que vulneren la mínima protección garantizada) o «semi-imperatividad» (son válidas las cláusulas más beneficiosas para el consumidor) y se trata de una nulidad en consonancia con el artículo 6 del CC.

\section{Integración con el conjunto del ordenamiento jurídico}

Las normas relativas a los contratos a distancia no regulan todas y cada una de las cuestiones atinentes a la modalidad específica de contrato, por lo que la regulación ha de integrarse con el ordenamiento jurídico español y, específicamente: con la propia LGDCU y con la Ley de Servicios de la Sociedad de la Información y Comercio Electrónico (LSSI) para aquellos contratos celebrados en el marco del comercio electrónico; y finalmente, en cuanto contrato, con las normas de Derecho privado.

El contrato a distancia puede ser de compraventa o suministro, arrendamiento de servicios o mixto (una combinación de los anteriores) y, en definitiva, cualquier tipo de contrato con tal de que se den los requisitos delimitadores de la noción legal. A los efectos que ahora interesan, se considera el contrato de compraventa, al ser el contrato de cambio por excelencia, que recibe regulación en ambos Códigos - el civil y el de comercio-; frente al arrendamiento de servicios que sólo está regulado en el civil.

En principio, si se está ante una compraventa realizada entre un empresario y un consumidor, ésta escaparía de la delimitación de la compraventa mercantil contenida en el artículo 325 CCom, a la vista de la literalidad del artículo 326.1 CCom. En este sentido se ha pronunciado reiteradamente la jurisprudencia ${ }^{7}$.

Pero incluso las compraventas para uso o consumo empresarial han sido calificadas como civiles por la jurisprudencia, pudiendo ser destacada la STS de 10 noviembre 2000 (RJ 2000, 9212), que contiene manifestaciones de la mayor trascendencia respecto de la compraventa civil y mercantil. El TS entiende que la venta de pienso que hace una cooperativa a una entidad socia de la misma, que se dedica

7 SSTS 20 noviembre 1984 [RJ 1984, 5617], 3 mayo 1985 [RJ 1985, 2257], 5 noviembre 1990 [RJ 1990, 8464], 30 noviembre 1994 [RJ 1994, 9168] y 18 marzo 1995 [RJ 1995, 1964]. 
a vender aves, no es mercantil. Cabe plantearse, en relación con esta Sentencia, si realmente el hecho de que el plazo de prescripción del Código civil (art. 1967.4 CC) sea mucho más corto -y adecuado al tráfico actual- que el general de quince años, que sería de aplicación a la compraventa mercantil, no está contribuyendo a que se califiquen las compraventas para uso o consumo empresarial como civiles.

En todo caso, los contratos a distancia celebrados con consumidores, en los aspectos contractuales de Derecho privado no previstos, tendrán como régimen subsidiario aplicable el Código civil. Y ello sin perjuicio de que el artículo 85 del Código de comercio sea de aplicación a este tipo de contratos, ya que el público comprador a que se refiere dicho artículo es cualquier adquirente, con independencia del destino a que se dedique el bien adquirido.

\section{Contratos electrónicos}

Los contratos electrónicos celebrados con consumidores son contratos a distancia por definición, siempre que el contrato electrónico en cuestión no esté excluido del ámbito de aplicación de la regulación de contratos a distancia por razón del objeto, por ejemplo.

En todo caso, conviene advertir que las disposiciones de la LSSI resultan de aplicación a los contratos a distancia, celebrados por vía electrónica, de conformidad con el artículo 94 LGDCU (que ha variado parcialmente el tenor literal del 38.6 LOCM en la "refundición»). El artículo 94 dispone lo siguiente: «en las comunicaciones comerciales por correo electrónico u otros medios de comunicación electrónica y en la contratación a distancia de bienes o servicios por medios electrónicos, se aplicará además de lo dispuesto en este título, la normativa específica sobre servicios de la sociedad de la información y comercio electrónico». Esto es, la normativa específica sobre comercio electrónico y la más general sobre contratos a distancia se aplicarán de manera concurrente, sin perjuicio de que si una disposición de la LSSI incidiera sobre un mismo aspecto regulado por la LGDCU, se aplicará entonces la LSSI preferentemente (vid. art. 94, párrafo $2^{\circ}$ ).

Recuérdese que, de conformidad con la LSSI, ha de entenderse por "vía electrónica» la transmisión "por medio de equipos electrónicos de tratamiento y almacenamiento de datos, conectados a una red de telecomunicaciones» [Anexo a dicha Ley, apartado h)]. 


\section{5. Ámbito subjetivo de aplicación de la regulación sobre contratos a distancia}

\subsection{Delimitación legal}

Un avance importante de la actual regulación resultante de la refundición consiste en una mejor delimitación del ámbito subjetivo de aplicación. En efecto, bajo la LOCM un problema fundamental que se planteaba era determinar si la regulación de los contratos a distancia en la LOCM se aplicaba a todos los destinatarios finales, coincidiendo con el ámbito general básico de la Ley, o si, por el contrario, se aplicaba únicamente a los consumidores. Y otro problema importantísimo consistía en determinar qué había de entenderse por "consumidor» a los efectos de la regulación que, en ese punto, se remitía al antiguo artículo $1^{\circ}$ de la LGDCU. Pues bien, hoy el texto refundido de la LGDCU ha proporcionado un concepto general de consumidor y de usuario aplicable a los contratos a distancia (art. 3 LGDCU) y ha solucionado eficazmente las preguntas que antes surgían.

En todo caso, la Directiva de 20 de mayo de 1997 delimita convenientemente las partes contratantes, el consumidor y el proveedor, pues el contrato a distancia, a los efectos del texto comunitario, es únicamente el celebrado entre ambos. La Directiva ha de servir para interpretar la regulación española, en aplicación del denominado "principio de interpretación conforme», sobre el que el TJCE se ha pronunciado en numerosas ocasiones ${ }^{8}$ y, según el cual, al aplicar las disposiciones de Derecho nacional, anteriores o posteriores a los textos comunitarios, el órgano jurisdiccional nacional debe interpretarlas a la luz del tenor literal y de la finalidad de dichos textos.

\subsection{El sujeto protegido: el consumidor}

En la Directiva 97/7/CE, se entiende por consumidor toda persona física que, en relación con las prácticas a que las disposiciones comunitarias se refieren, actúa fuera de su actividad profesional, entendida ésta como actividad contrapuesta a la esfera privada. Se trata de una noción concreta y funcional, que, a la vista de la jurisprudencia del Tribunal de Justicia de la Comunidades Europeas

${ }^{8}$ Vid., entre otras, la STJCE de 27 junio 2000 [TJCE 2000, 144]. 
en materia de protección de los consumidores ${ }^{9}$, ha de ser interpretada de forma restrictiva. El sujeto protegido ha de ser una "persona física», de manera que quedan excluidas de la noción comunitaria de consumidor las personas jurídicas.

Como es sabido, la LGDCU contiene una noción en el artículo 3, que el propio texto refundido vigente denomina «concepto general de consumidor y de usuario»: "son consumidores o usuarios las personas físicas o jurídicas que actúan en un ámbito ajeno a una actividad empresarial o profesional». Ese «concepto general» no ha de regir para todo tipo de operaciones, sino sólo para el ámbito de la propia LGDCU, o bien cuando una Ley se remita expresamente a ella. Ha de retenerse, por tanto, que la noción de consumidor que rige para la regulación de los contratos a distancia es la contenida en dicho artículo 3 LGDCU y, en cambio, la noción que rige para la comercialización a distancia de servicios financieros regulados por la Ley 22/2007 (en adelante, LSFD), de 11 de julio, es la contenida en el artículo 5 de dicha Ley ${ }^{10}$. Ambas nociones difieren en un aspecto concreto: la LGDCU considera consumidor tanto a las personas físicas como jurídicas, mientras que la noción de la LSFD — que sigue la Directiva a cuya transposición obedece- - se ciñe a las personas físicas.

Ha de recordarse al respecto que, en la mayoría de los ordenamientos jurídicos europeos, la noción de consumidor queda restringida a las personas físicas, en consonancia con la tendencia apreciada en las Directivas comunitarias. Pero también ha de recordarse que el legislador español al llevar a cabo el texto refundido de la LGDCU no contaba con habilitación suficiente para modificar o alterar el concepto de consumidor contenido en el antiguo artículo 1, apartados 2 y 3 , hasta el grado de suprimir la mención de las personas «jurídicas». Lo que sí ha hecho el legislador es traer a nuestro ordenamiento un concepto similar al comunitario, con la salvedad indicada y ello a pesar de que la antigua redacción era bastante más compleja que la actual. Redacción que, sin embargo, permitía ser interpretada en el sentido de considerar consumidores o usuarios tanto las personas físicas como jurídicas cuando sean destinatarios fi-

9 Vid. SSTJCE de 14 marzo 1991, Asunto Di Pinto [TJCE 1991, 155], 17 marzo 1998, Asunto Dietzinger [TJCE 1998, 52], 23 marzo 2000, Asunto Berliner Kindl Brauerei AG c. Andreas Siepert, As. C-208/98, y 22 noviembre 2001, Asunto Cape/Idealservice [TJCE 2001, 330].

10 Vid. ARROYO APARICIO, A., "Análisis crítico de la normativa relativa a la comercialización a distancia de servicios financieros destinados a los consumidores», Tendencias actuales en torno al mercado del crédito, PULGAR, J. (Dir.), Marcial Pons, 2010, pp. 339 a 368. 
nales de los bienes o servicios que adquieren fuera del ámbito de su actividad empresarial o profesional, entendiendo ésta en sentido amplio como contraposición a la esfera privada, familiar o personal.

En relación con este último aspecto, han de ser citadas algunas sentencias referidas a la antigua LGDCU. Así, la STS de 18 junio 1999 (RJ 1999, 4478) en la que se declara que no ostenta la condición de consumidor una sociedad agraria de transformación que adquiere unos herbicidas para integrarlos en el proceso productivo agrícola a fin de vender con posterioridad los productos obtenidos. Esa integración en el proceso productivo hace que la sociedad agraria no sea destinatario final y no pueda, en consecuencia, beneficiarse de las normas de protección de los consumidores. En idéntica dirección en la STS de 16 octubre 2000 (RJ 2000, 9906) se considera que no resulta aplicable la LGDCU ya que están excluidos de su ámbito «quienes adquieren los bienes sin constituirse en destinatarios finales, para integrarlos en actividades empresariales o profesionales», quedando claro en el supuesto de autos en el que se había adquirido una impresora "para una actividad de publicación, y no para un mero uso doméstico o personal».

No parece correcta, en cambio, la STS de 21 septiembre 2004 (RJ 2004, 5576) en la que se considera que un empresario agrícola tiene la consideración de consumidor en relación con la compra de un tractor por el solo hecho de ser una persona física, alegándose al respecto una sesgada y equivocada interpretación de la STJCE de 22 noviembre 2001 (TJCE 2001, 330).

\subsection{El empresario y profesional}

El consumidor es sólo una de las partes contratantes y su protección se establece siempre frente al "profesional», entendido éste en sentido amplio. Éste es el criterio que ha seguido el legislador comunitario al considerar que por "proveedor» ha de entenderse toda persona física o jurídica que actúa dentro del marco de su actividad profesional. Es decir, cualquier persona que realiza operaciones en el mercado, incluidos los profesionales, los empresarios individuales o sociales, con tal de que cuenten con un sistema organizado a distancia para ofrecer sus bienes o servicios.

La LGDCU emplea el término de "empresario», que incluye, en sentido similar al comunitario apuntado, «toda persona física o jurídica que actúa en el marco de su actividad empresarial o profesional, ya sea pública o privada» (art. $4^{\circ}$ LGDCU). 


\section{6. Ámbito objetivo de aplicación de la regulación sobre contratos a distancia}

\subsection{Requisitos delimitadores de los contratos a distancia}

En la LGDCU se dispone que «se regirán por lo dispuesto en este título los contratos celebrados con los consumidores y usuarios en el marco de una actividad empresarial, sin la presencia física simultánea de los contratantes, siempre que la oferta y aceptación se realicen de forma exclusiva a través de una técnica de comunicación a distancia y dentro de un sistema de contratación a distancia organizado por el empresario». Así mismo, se añade un segundo párrafo al artículo 92.1, según el cual «la validez y eficacia de los contratos relativos a bienes inmuebles quedará condicionada, además, al cumplimiento de los requisitos que impone su legislación específica».

Antes de analizar los requisitos delimitadores del concepto, conviene hacer varias precisiones en cuanto a los contratos incluidos y el objeto del contrato. En primer lugar, en cuanto a los contratos incluidos, puede observarse que la LGDCU se refiere genéricamente a los "contratos a distancia», abandonando la antigua expresión de la LOCM en términos de "venta», lo que resulta más correcto y adecuado a la Directiva 97/7. Por tanto, los tipos de contratos sometidos al régimen legal son el contrato de compraventa y el de arrendamiento de servicios, así como las compraventas con prestación de servicios accesorios o a la inversa. Tampoco plantea problemas el admitir que los contratos de suministro quedan sometidos a la regulación (cfr. art. 93.2 que excluye algunos — no todos- los contratos de suministro), si se tiene en cuenta que podría tratarse, por ejemplo, de suscripciones o entregas periódicas que suelen realizarse sobre catálogos. Del mismo modo cabe entender que está incluido el arrendamiento de obra, distinto del que tenga por resultado la construcción de un inmueble, que queda expresamente excluido [art. 93.1.e)].

En conclusión, a la vista de los posibles contratos incluidos, resulta claro que lo determinante para la calificación de "contrato a distancia» no es tanto el tipo de contrato cuanto los sujetos contratantes y, principalmente, el modo de celebración del contrato. Es decir, no ha de estarse a la prestación característica del tipo contractual, sino que el contrato se identifica por otras circunstancias ajenas a dicha prestación.

En segundo lugar, por lo que respecta al objeto del contrato, ha de mencionarse que la LGDCU no determina de forma expresa cuál ha 
de ser el mismo, pudiéndose deducir, no obstante, que aquél está constituido por bienes muebles o mercaderías, por bienes inmuebles (nótese que la referencia a los inmuebles está expresamente citada en el artículo 92.1) o por servicios.

De la delimitación que el artículo 92.1 LGDCU realiza respecto de qué ha de entenderse por "contratos a distancia», se deduce la concurrencia de tres requisitos objetivos de inclusión (i) la existencia de un sistema de contratación a distancia; (ii) la falta de presencia física simultánea de las partes contratantes; y (iii) la utilización exclusivamente de técnicas de comunicación a distancia hasta la celebración del contrato.

A) Sistema de contratación a distancia: significado. La existencia del «sistema» de contratación a distancia resulta fundamental para distinguir los supuestos que han de considerarse incluidos en el ámbito de aplicación, de los que no lo están ${ }^{11}$. Así, por ejemplo, no se consideraría "contrato a distancia» el celebrado entre un consumidor y un comerciante «tradicional», aun cuando el contrato se celebre por teléfono (operación ocasional a distancia), si dicho comerciante no dispone de una estructura específica para comunicarse y contratar con sus clientes sirviéndose de una o varias técnicas de comunicación a distancia (como pudieran ser una página web a través de la cual se pueda contratar o un catálogo de venta). Del mismo modo, no puede considerarse que se cuente con una estructura específica para contratar si la empresa tan sólo se anuncia utilizando un medio de comunicación, por ejemplo, en páginas amarillas, prensa, radio, televisión o incluso una página web, si no es más que a efectos publicitarios.

Por otra parte, ha de tenerse en cuenta que la exigencia legal no implica en ningún caso que el proveedor utilice exclusivamente ese sistema para ofrecer sus bienes o servicios, esto es, puede contar además con un establecimiento abierto al público.

B) Falta de presencia física simultánea de las partes contratantes. Según la LGDCU son contratos a distancia los celebrados «sin presencia física simultánea de los contratantes» (art. 92.1), por lo que el momento relevante a efectos de observar la concurrencia de este re-

11 V. GOYENS, M., «L'impact en droit belge de la future directive concernant la protection des consommateurs en matière de contrats négociés a distance», $D C C R$, núm. 30, 1996, p. 18; FUCHS, A., «Das Fernabsatzgesetz im neuen System des verbraucherschutzrechts», ZIP, 30/2000, pg. 1275; WALDENBERGER, A., "Alles schwebend unwirksam -Distanzgeschäfte nach dem Referentenentwurf eines Fernabsatzgesetzes», $K \& R, 8 / 1999$, pp. 345 a 354 , en concreto, p. 346. 
quisito es fundamentalmente el de la celebración del contrato. Téngase en cuenta que en la tradición jurídica española el término «celebración» es asimilable a "perfeccionamiento» del contrato o momento de concurrencia de la oferta y la aceptación.

Ahora bien, no parece dudoso que la falta de presencia simultánea de las partes se dará normalmente tanto en la negociación como, por supuesto, en la celebración. Incluso, así parece presuponerlo el legislador porque: en primer lugar, la falta de presencia en la celebración ya viene impuesta por la transmisión de la oferta y de la aceptación a través de una técnica cualquiera de comunicación a distancia, como también exige el propio artículo 92.1; en segundo lugar, porque una interpretación sistemática de la Ley así lo indica; y en tercer lugar, porque esta interpretación estaría en consonancia con la Directiva 97/7 que, al definir el contrato a distancia, dispone que es aquel en el que se utiliza exclusivamente una o más técnicas de comunicación a distancia hasta la celebración del contrato, incluida la celebración del mismo (art. 2.1 de la Directiva).

En todo caso, queda claro que, por ejemplo, no sería un contrato a distancia aquel en el que un consumidor recibe un catálogo pero se desplaza al establecimiento del empresario para perfeccionar el contrato. Más dudas plantea el caso en el que el empresario muestra sus productos en una exposición o feria, pero los vende a través de un sistema a distancia. Este supuesto debería resolverse en favor de su consideración de contrato a distancia si existe un «sistema organizado a distancia», ya que éste hace presuponer que la presencia física - a efectos contractuales- no se dará tampoco antes de la celebración del contrato. Es decir, la falta de presencia física simultánea es un requisito del contrato. Recuérdese además que el «sistema organizado» sirve para dejar fuera del ámbito de aplicación las operaciones ocasionales y para deslindar la mera promoción (anuncios en páginas amarillas, publicidad en general) de una organización específica encaminada a comunicarse con los posibles clientes y contratar con ellos a distancia, utilizando a tal fin una o varias técnicas de comunicación.

¿Y qué ocurre con la ejecución del contrato?, ¿ha de ser también a distancia? La ejecución del contrato puede o no ser a distancia; cuando el objeto del contrato sea un bien será más frecuente, pero en cualquier caso no queda incluida en la delimitación del contrato a distancia la exigencia de que el cumplimiento o ejecución del contrato sea también a distancia. De ahí, precisamente, que si sólo se da esa circunstancia, el contrato no será a distancia a no ser que se haya negociado y perfeccionado de tal manera. 
C) Utilización de técnicas de comunicación a distancia. De conformidad con el artículo 92.1 LGDCU, la oferta y la aceptación deben transmitirse «de forma exclusiva a través de una técnica cualquiera de comunicación a distancia», debiendo entenderse que no es preciso que coincida la técnica empleada para transmitir una y otra. El único requisito que han de cumplir las técnicas es que sean aptas para transmitir las declaraciones de voluntad contractuales sin presencia física simultánea de las partes, no restringiéndose a las técnicas que conocemos actualmente. Las que ya se utilizan hoy pueden clasificarse en cuatro categorías: la primera, medios en soporte documental que permiten comunicarse a distancia (impreso con o sin destinatario, carta normalizada, publicidad en prensa con cupón de pedido y catálogo); la segunda, comunicaciones telefónicas o transmitidas por teléfono (teléfono con intervención humana, teléfono sin intervención humana - llamadas automáticas-, teléfono con imagen y fax); la tercera, comunicaciones a través de televisión o radio; y la cuarta, comunicaciones por vía electrónica (correo electrónico o a través de páginas web). La LGDCU cita, a modo de ejemplo, las mayoría de las expuestas en el artículo 91.2.

El legislador considera que el empleo de algunas técnicas de comunicación requiere normas protectoras específicas en beneficio del consumidor, ya que incluso pueden ser menos aptas para acreditar la prueba de la celebración del contrato y del cumplimiento de los requisitos legales. En concreto, el artículo 96 LGDCU se refiere a las "comunicaciones comerciales", en el que se exige que en las mismas conste inequívocamente su carácter comercial. También se alude a las comunicaciones telefónicas y en el apartado tercero se dispone el sistema de consentimiento previo ${ }^{12}$ para las comunicaciones que se realicen a través de sistemas sin intervención humana o fax.

En el caso de comunicaciones telefónicas, el artículo 96.2 LGDCU dispone que deberá precisarse explícita y claramente, al principio de cualquier conversación con el consumidor y usuario, la identidad del empresario y la finalidad comercial de la llamada. Se persigue así que el consumidor pueda decidir desde el primer momento si desea o no continuar con la conversación. A primera vista se aprecia que el cumplimiento o no del extremo previsto en el artículo citado será de difícil comprobación, y más que una norma de protección del

12 Conocido como sistema opt-in, que implica el consentimiento previo: REICH, N., «Die neue Richtlinie 97/7/EG über den Verbraucherschutz bei Vertragabschlüss im Fernabsatz», EuZW, 19/1997, p. 451. 
consumidor podría considerarse como un principio de corrección en el tráfico perteneciente al Derecho de la competencia.

Para la recepción de ofrecimientos comerciales a través de llamadas sin intervención humana o fax se ha dispuesto, en cambio, que será preciso el consentimiento previo del consumidor (art. 96.3 LGDCU). Este consentimiento puede prestarse, por ejemplo, a través de impresos especiales, una cláusula al efecto o un cupón de respuesta. Evidentemente no es necesario que sea por escrito, sino que sea previo, pudiéndose deducir - eso sí- que sea expreso y pueda ser acreditado. Resulta razonable considerar que la prueba del cumplimiento de este extremo debería corresponder al empresario, pues es quien estará en condiciones de acreditarlo más fácilmente y sobre quien pesa el deber de recabar el consentimiento.

Nada ha previsto el legislador en cuanto a la prueba, pero sí que ha establecido la consideración de infracción - con la consiguiente sanción administrativa - para el caso de no haber recabado el consentimiento previo cuando fuera exigible [art. 49.2.b) LGDCU].

Aparte de los dos supuestos citados, el apartado $4^{\circ}$ del artículo 96 establece que "cuando se utilicen datos personales procedentes de fuentes accesibles al público para la realización de comunicaciones comerciales, se proporcionará al destinatario la información que señala la Ley Orgánica de Protección de Datos de carácter personal (LOPD), y se ofrecerá al destinatario la oportunidad de oponerse a la recepción de las mismas».

\subsection{Exclusiones del ámbito objetivo de aplicación de la regulación sobre contratos a distancia}

La delimitación del ámbito objetivo de aplicación se completa estableciendo una relación de supuestos expresamente excluidos. Estos supuestos pueden clasificarse en exclusiones totales (totalmente excluidos del ámbito de aplicación) o parciales (solamente excluidos de la aplicación de algunas de las disposiciones).

A) Exclusiones totales del ámbito de aplicación. a) Servicios financieros. Por razón del objeto sobre el que recaen, resultan excluidos del ámbito de aplicación los contratos de prestación de servicios financieros. En concreto, en la LGDCU se dispone que «la regulación establecida en este título no será de aplicación a (...) los contratos sobre servicios financieros » [art. 93.1.c)]. Téngase en cuenta que estos servicios han merecido un tratamiento diferenciado en el ámbito co- 
munitario a través de la Directiva 2002/65/CE del Parlamento y del Consejo relativa a la comercialización a distancia de servicios financieros destinados a los consumidores. Directiva que, en todo caso, se ha incorporado tardíamente al ordenamiento español, tal y como se declaró en la STJCE de 19 abril 2007 (JUR 2007, 101682). En efecto la norma comunitaria ha sido incorporada por Ley 22/2007, de 11 de julio, sobre comercialización a distancia de servicios financieros destinados a los consumidores.

b) Contratos relativos a los bienes inmuebles. La LGDCU también excluye de su ámbito de aplicación los contratos «celebrados para la construcción de bienes inmuebles» [art. 93.1.e)]. Cabe entender que la exclusión obedece al objeto sobre el que recaen, así como a las peculiaridades del contrato en sí, ya que ha de destacarse que en relación con los bienes inmuebles la exclusión no es absoluta. A este respecto, cabe señalar que el legislador ha evitado pronunciarse claramente sobre otros contratos relativos a los bienes inmuebles que no sea el de construcción, y ha dado por resuelta la problemática con el artículo 93.1 $2^{\circ}$ párrafo, según el cual: «la validez y eficacia de los contratos relativos a bienes inmuebles quedará condicionada, además, al cumplimiento de los requisitos que impone su legislación específica».

En resumen, los contratos celebrados para la construcción de bienes inmuebles están excluidos del ámbito de aplicación, mientras que otros contratos relativos a inmuebles quedan sometidos a la regulación, con las peculiaridades previstas si se trata de contratos de prestación de servicios.

La compraventa de inmuebles no se ha excluido expresamente, aunque podría considerarse incompatible con la noción de contrato a distancia. Puede hacerse notar que en otras normas de protección de los consumidores se han previsto disposiciones específicas para el caso de que el contrato conste en documento notarial, como ocurre en materia de aprovechamiento por turno de bienes inmuebles (cfr. art. 10.3 in fine Ley 43/1998, de 15 de diciembre). En cambio, los «contratos documentados notarialmente» se excluyen del ámbito de los contratos celebrados fuera de los establecimientos mercantiles [art. 108.f) LGDCU], en la consideración de que la intervención de fedatario público ha de ser suficiente para proporcionar al consumidor un mayor grado de garantía.

c) Contratos realizados a través de distribuidores automáticos o locales comerciales automatizados. En la LGDCU se establece que lo dispuesto en ella para las "contratos a distancia» no será de aplicación a «las ventas celebradas mediante distribuidores automáticos o 
locales comerciales automatizados» [art. 93.1.a)]. La exclusión adolece de un excesivo apego al contrato de compraventa, pero cabe entender que quedan excluidos los contratos - y no sólo las ventas- realizados a través de los medios citados. En este sentido, piénsese que la exclusión ha de vincularse tanto a las «máquinas expendedoras» de comidas y bebidas, como, por ejemplo, a las «terminales» que, mediante el pago de un precio, permiten el acceso a internet o a las máquinas expendedoras de billetes de transportes.

Parece razonable plantearse si en realidad los contratos realizados a través de los «distribuidores automáticos» quedan propiamente dentro de la noción de "contrato a distancia», pues dichos distribuidores no son en rigor técnicas de comunicación. En todo caso, este tipo de contratos plantea una problemática diferente (problemas técnicos o de seguridad, por ejemplo) y reciben además regulación específica en la LOCM (arts. 49 a 52). La problemática diferente, así como las circunstancias que rodean a la celebración y ejecución del contrato - casi simultáneas- pueden considerarse como razones que justifican la exclusión legal.

d) Contratos celebrados con los operadores de telecomunicaciones a través de teléfonos públicos. Muy cercana a la anterior exclusión se encuentra la relativa a los contratos celebrados con los operadores de telecomunicaciones a través de teléfonos públicos. La LGDCU excluye del ámbito de la regulación sobre contratos a distancia los contratos «celebrados con los operadores de telecomunicaciones debido a la utilización de teléfonos públicos» [93.1.d)].

El supuesto se refiere al uso de los teléfonos públicos, supuesto que escapa claramente de la problemática específica de la contratación a distancia. No se trata sólo de que en estos contratos la prestación se realice de forma casi instantánea, lo que es incompatible con el ejercicio del derecho de desistimiento, sino más bien que la normativa sobre contratos a distancia excede en general de la protección requerida para estas operaciones. Operaciones que se concretan en supuestos tan comunes como utilizar un teléfono público a cambio de una moneda.

Como puede apreciarse, en el anterior supuesto (supra c) y en el aquí tratado, la exclusión se justifica por las circunstancias que rodean a la celebración y ejecución del contrato, así como por la problemática que plantean, lejana en sí de la protección otorgada a los consumidores en los contratos a distancia (tanto en materia de información y confirmación escrita, como del derecho de desistimiento). 
e) Contratos celebrados en subastas. Los contratos celebrados en subastas, excepto las efectuadas por vía electrónica, están excluidos de la regulación [art. 93.1.b) LGDCU]. En esta ocasión la exclusión parece obedecer a que los contratos celebrados en subastas presentan peculiaridades específicas. De hecho, la LOCM dedica a estos contratos los artículos 56 a 61. Por una parte, resulta claro que, en unas ocasiones, el contrato celebrado en subastas escapará de la consideración de contrato a distancia; y de otra, que la fijación del precio mediante el sistema de pujas no resulta compatible con el ejercicio del derecho de desistimiento. Efectivamente, el derecho de desistimiento no puede ser utilizado para especular en perjuicio del empresario; ni la devolución del bien debe implicar la ruptura de la equivalencia de las prestaciones. No cabe ignorar que la empresa subastadora no tiene la seguridad de obtener el mismo precio en una puja posterior.

En cuanto a las subastas electrónicas, sí que quedan sometidas a la aplicación de la LGDCU, aunque evidentemente no lo estarían aquellas que se celebran en relación con servicios financieros, que están totalmente excluidos del ámbito de aplicación.

B) Exclusiones parciales del ámbito de aplicación. Junto con las exclusiones totales, la LGDCU recoge dos supuestos a los que no son de aplicación las siguientes normas de protección del consumidor: (i) los artículos 96.1 y 2 relativos a las comunicaciones comerciales; (ii) el artículo 97 destinado a regular la información que se ha de facilitar al consumidor previamente a la celebración del contrato; (iii) el artículo 98 sobre confirmación escrita de la información; (iv) el artículo 101 que regula el derecho de desistimiento; y (v) el artículo 103 que se refiere al plazo de ejecución del contrato.

La exclusión parcial de los supuestos analizados a continuación parece encontrar su justificación en que determinados contratos, vinculados a determinados objetos, merecen tan sólo una protección parcial ya que, principalmente, la naturaleza del objeto sobre el que recaen resulta incompatible con el ejercicio del derecho de desistimiento.

a) Contratos que tengan por objeto la entrega de bienes de consumo corriente en el hogar. El artículo 93.2.a) LGDCU dispone que los artículos citados no serán de aplicación a «los contratos de suministro de productos alimenticios, de bebidas o de otros productos del hogar de consumo corriente suministrados en el domicilio del consumidor, en su residencia o en su lugar de trabajo por distribuidores que realicen visitas frecuentes y regulares». Se trata de operaciones 
desarrolladas en el marco de una práctica frecuente sobre bienes de escaso valor, pretendiendo en último término no añadir una carga excesiva a los proveedores, pero sí un mínimo de garantías.

Nótese que se ha reproducido casi literalmente el artículo 108.g) referido a los contratos celebrados fuera de los establecimientos mercantiles, que obedeció a su vez a la constatación de la práctica consistente en distribuir a domicilio los bienes de consumo corriente, todo ello de forma continuada (de ahí la expresión «visitas frecuentes y regulares»). Esa práctica, propia en un principio de zonas rurales, escapaba del ámbito de protección, requerido sólo para supuestos en los que el consumidor se encontraba desprevenido frente a la celebración de un contrato.

Parece, por tanto, que la transcripción mimética de la exclusión no está del todo justificada. Ya que, en el ámbito de los contratos a distancia, ¿qué significa la alusión a los «distribuidores que realicen visitas frecuentes y regulares»?, ¿ha de entenderse que si no realizan tales visitas, entonces el supuesto queda sometido a la regulación? Resulta razonable entender que la intención del legislador es dejar fuera del ámbito los contratos sobre este tipo de bienes que por su naturaleza son claramente incompatibles con el derecho de desistimiento y respecto de los cuales resulta excesivo cargar a los proveedores con la confirmación escrita de determinados datos.

b) Contratos de prestación de servicios relativos a alojamiento, transporte, comidas y actividades de recreo. El artículo 93.2.b) LGDCU ha dispuesto que las normas relacionadas al inicio de este epígrafe no serán de aplicación a «los contratos de suministro de servicios de alojamiento, de transporte, de comidas o de esparcimiento, cuando el empresario se comprometa al celebrarse el contrato a suministrar tales prestaciones en una fecha determinada o en un período concreto».

Se trataría de supuestos como, por ejemplo, la compra de una entrada para asistir a un espectáculo, llamar a un «tele-taxi» o solicitar una "pizza» por teléfono; supuestos todos en los que hay un compromiso de llevar a cabo la prestación en un momento o período determinado. Y, pudiendo ser el período que media entre la celebración del contrato y la prestación muy corto, resulta incompatible con el ejercicio del derecho de desistimiento, ya que sería imposible para el empresario reintroducir el servicio en el mercado. En relación con estos supuestos, ha de citarse la STJCE de 10 marzo 2005 (Asunto easyCar, que se analizará detenidamente en el apartado III), en la que se considera que los contratos de servicios de alquiler 
de vehículos han de entenderse "servicios de transporte» a los efectos de su exclusión parcial del ámbito de aplicación de la Directiva 97/7/CE.

\section{Especialidades en la formación del contrato}

La formación del contrato a distancia es una cuestión de extraordinaria importancia en este tipo de contratación. La LGDCU regula algunos aspectos que inciden en la formación de los contratos a distancia, pero no el momento ni el lugar de perfeccionamiento de dichos contratos. El perfeccionamiento del contrato a distancia debe ser resuelto, por tanto, de conformidad con el Derecho codificado, sin olvidar tampoco la normativa en materia de comercio electrónico y condiciones generales de contratación.

\subsection{Aplicación del Derecho codificado y de la LSSI}

El contrato a distancia se perfecciona, como cualquier otro contrato que no sea ni formal ni real, mediante el consentimiento prestado por los contratantes manifestado por el concurso de la oferta y la aceptación sobre el objeto y la causa que han de constituir el contrato (arts. 1254, 1261 y $1262 \mathrm{CC}$ ). Y ello sin perjuicio de la existencia del derecho de desistimiento.

Estos contratos, caracterizados por la falta de presencia simultánea de las partes y la transmisión de las declaraciones de voluntad a través de técnicas de comunicación a distancia, encuentran acomodo en las categorías tradicionales de contratos entre personas «distantes», sean de formación instantánea (contratos celebrados por teléfono) o de formación sucesiva. Pero, en todo caso, lo más importante es que el criterio de determinación del momento y lugar de perfeccionamiento ha de buscarse en el Derecho codificado, puesto que la LGDCU no prevé ninguna norma específica.

Como es sabido, las normas aplicables a la determinación del momento y lugar del contrato celebrado entre dos personas que se hallen en lugares distintos son el artículo 1262 CC y el 54 CCom. Normas que seguían un criterio dispar hasta su unificación con ocasión de la modificación de ambos artículos por la LSSI (cfr. disposición final cuarta LSSI). Con esta unificación de criterio, la solución al problema de determinación del momento y lugar de perfeccionamiento del contrato entre personas que se hallen en lugares distintos 
es, por tanto, la misma, sea cual sea la calificación, civil o mercantil, del contrato. El legislador aprovechó la ocasión de la LSSI para modificar el Derecho codificado al respecto, Derecho que resulta no sólo de aplicación a los contratos electrónicos, sino en general a cualquier contrato a distancia. Para el caso de que el contrato a distancia sea un contrato celebrado "por vía electrónica», serán de aplicación entonces las particularidades previstas en la LSSI.

El artículo $1262 \mathrm{CC}$, en su primer párrafo, dispone la regla general en materia de perfeccionamiento del contrato: el consentimiento se manifiesta por el concurso de la oferta y de la aceptación sobre la cosa y la causa que han de constituir el contrato. Literalmente, no se precisa cuál es la regla de perfeccionamiento en términos de emisión, expedición o conocimiento de la declaración de voluntad que cierra el «iter» formativo del contrato: la aceptación. Pero ello es absolutamente lógico si se tiene en cuenta que, estando ambas partes presentes o utilizando un medio de comunicación que permita ésta inmediatamente (el teléfono, por ejemplo), el momento de perfeccionamiento - de coincidencia o concurso- del contrato es único: si es oralmente, no es preciso distinguir entre la declaración del aceptante y el conocimiento de ésta por el oferente, por ser, además de inapreciable, irrelevante jurídicamente.

Para los contratos a distancia, habrán de ser tenidos en consideración los dos últimos párrafos del artículo $1262 \mathrm{CC}$, coincidentes con los dos únicos del artículo 54 CCom. Así, para el caso en que se hallaren «en lugares distintos el que hizo la oferta y el que la aceptó, hay consentimiento desde que el oferente conoce la aceptación o desde que habiéndosela remitido el aceptante, no pueda ignorarla sin faltar a la buena fe» (arts. 1262, $2^{\circ}$ párr. CC y 54 párr. $\left.1^{\circ} \mathrm{CCom}\right)$. En consecuencia, el contrato se entiende perfeccionado cuando el oferente conoce la aceptación, o se reputa que tal conocimiento ha tenido lugar cuando el oferente la pudo conocer.

Téngase en cuenta que, aunque el texto haya recibido críticas, puede manifestarse que se mantiene el criterio anteriormente recogido por el Código civil de manera similar a como venía siendo interpretado por la jurisprudencia y la doctrina, es decir, se consagra legalmente una solución acorde con la teoría del conocimiento, solución que se ve atemperada por la aplicación, en su caso, de una norma que aproxima la solución legal a la teoría de la recepción.

Junto con la anterior norma, ambos Códigos disponen igualmente que en los contratos «celebrados mediante dispositivos automáticos hay consentimiento desde que se manifiesta la aceptación» (arts. 
1262 , párr. $3^{\circ} \mathrm{CC}$ y 54 , párr. $\left.2^{\circ} \mathrm{CCom}\right)$. De manera que esta norma resultará de aplicación cuando se utilicen «dispositivos automáticos», expresión que no se ha aclarado en las definiciones que se adjuntan a la LSSI (aunque el término "dispositivo» sí que se utiliza en el artículo 28.3 LSSI). Cabe considerar que tal vez no se haya incluido la definición porque la referencia está contenida en la disposición adicional cuarta por la que se modifica el Derecho codificado y no en el texto articulado de la LSSI. Y, tal y como se manifiesta en la Exposición de Motivos de la LSSI, «se aprovecha la ocasión para fijar el momento y lugar de celebración de los contratos electrónicos, adoptando una solución única, también válida para otros tipos de contratos celebrados a distancia, que unifica el criterio dispar contenido hasta ahora en los Códigos civil y de comercio» (la cursiva no figura en el original).

En todo caso, la norma se aplica a los contratos en los que se utilicen «dispositivos» que operan de forma automática a efectos de la celebración del contrato, esto es, en los que el intercambio de oferta y aceptación se produce de forma inmediata en virtud del dispositivo mismo.

Tanto el artículo $1262,2^{\circ}$ párrafo CC como el 54 , párrafo $1^{\circ} \mathrm{CCom}$ son claros al disponer para todo contrato celebrado entre dos partes que se hallaren en lugares distintos que el mismo «se presume celebrado en el lugar en que se hizo la oferta». Al tratarse de una presunción, se permite que se pruebe un lugar distinto correspondiendo - eso sí- la carga de la prueba al que mantenga que el lugar no es el de emisión de la oferta. Así mismo, cabe entender que la norma no limita la libertad de las partes para pactar el lugar de celebración del contrato.

Obsérvese que la solución legal considera como lugar de perfeccionamiento el de aquel en el que se encontraba el que tomó la iniciativa al contratar. Obviamente puede ocurrir que el oferente conozca la aceptación en otro lugar distinto a aquel en el que hizo la oferta. En definitiva, la presunción se da con independencia de si se corresponde con el lugar en el que está el oferente en el momento de perfeccionamiento.

En relación con la contratación electrónica se ha previsto que el lugar de celebración se considerará el de residencia habitual del consumidor en los contratos celebrados por éste, mientras que en los contratos celebrados entre empresarios o profesionales, el lugar será el que pacten éstos o, en su defecto, el lugar en que esté establecido el prestador de servicios (art. 29 LSSI). 
Se observa, de inmediato, que para los contratos electrónicos se ha previsto una norma específica de determinación del lugar (art. 29 LSSI), mientras que no es así para el resto de contratos a distancia celebrados por consumidores empleando otros medios, en los que deberá determinarse en virtud de las reglas generales.

Una de las particularidades más importantes que ha previsto la LSSI consiste en que el "oferente está obligado a confirmar la recepción de la aceptación al que la hizo» (art. 28.1 LSSI). Esta norma es aplicable imperativamente cuando el contratante sea consumidor, ya que si ninguna de las partes lo es pueden pactar otra cosa (art. 28.3 LSSI). En todo caso, no resulta obligatoria la confirmación de la recepción de la aceptación cuando el contrato se haya celebrado exclusivamente mediante intercambio de correo electrónico u otro tipo de comunicación electrónica equivalente, siempre que «estos medios no sean empleados con el exclusivo propósito de eludir el cumplimiento de tal obligación» [art. 28.3 b) LSSI].

Evidentemente dicha confirmación no supone una posposición del momento de perfeccionamiento del contrato. El contrato se perfecciona con el concurso de la oferta y aceptación, de manera que se está ante una mera confirmación de la recepción de la aceptación, tal y como se deduce del artículo 28 de la LSSI. Según dicho artículo «el oferente está obligado a confirmar la recepción de la aceptación al que la hizo», a través del "envío de un acuse de recibo por correo electrónico u otro medio de comunicación electrónica equivalente a la dirección que el aceptante haya señalado, en el plazo de las veinticuatro horas siguientes a la recepción de la aceptación», o "por un medio equivalente al utilizado en el procedimiento de contratación (...) tan pronto como el aceptante haya completado dicho procedimiento, siempre que la confirmación pueda ser archivada por su destinatario» [art. 28.1 a) y b) LSSI].

La confirmación resulta útil a los fines de certeza de la recepción de la aceptación y ambas —confirmación y recepción de la aceptación- se entienden producidas «cuando las partes a que se dirijan puedan tener constancia de ello». Así mismo «en el caso de que la recepción de la aceptación se confirme mediante acuse de recibo, se presumirá que su destinatario puede tener la referida constancia desde que aquél haya sido almacenado en el servidor en que esté dada de alta su cuenta de correo electrónico, o en el dispositivo utilizado para la recepción de comunicaciones» (art. 28.2 LSSI).

Con todo, la regulación en materia de «confirmación» ha de ser valorada negativamente en cuanto a la confusión de los términos en 
ella contenidos; confusión que resulta predicable, en general, de la LSSI y, en especial, respecto de qué ha de entenderse por «destinatario». De manera que, según el artículo $28.1 .2^{\circ}$ párrafo, la «confirmación» puede corresponder igualmente a un "destinatario de servicios», mientras que en la Directiva 2000/31, sobre comercio electrónico, el obligado a "confirmar» es el prestador de servicios (art. 11.1 Dir. 2000/31). Téngase en cuenta además que, de conformidad con la LSSI, el incumplimiento de la obligación de "confirmación» constituye infracción administrativa que es susceptible de sanción a la que están sujetos los «prestadores de servicios» (arts. 37 y ss. LSSI).

\subsection{Información previa exigible}

Aparte del problema del perfeccionamiento del contrato, la LGD$\mathrm{CU}$ regula aspectos que sí que inciden en la formación del mismo. Se trata del deber de información previa que el empresario ha de cumplir en beneficio del consumidor. Así, se exige que el empresario informe al consumidor de determinados datos, lo que es de extraordinaria importancia pues en función de dicha información el consumidor ha de estar en condiciones de tomar una decisión económica razonada (me interesa comprar o no). Para el caso de los contratos electrónicos, la LSSI exige además que, antes del inicio del procedimiento de contratación, el prestador de servicios facilite al consumidor algunas menciones en atención al medio.

Por otra parte, téngase en cuenta que la información previa puede estar contenida en condiciones generales predispuestas por el empresario o cláusulas no negociadas individualmente con el consumidor ${ }^{13}$.

A) Significado e incidencia de la información previa en la formación del contrato. Con carácter previo, conviene aclarar que la regulación contenida en la LGDCU, al delimitar el contrato a distancia, no atribuye la posición de oferente al empresario y la de aceptante al consumidor (art. 92). Y lo hace acertadamente, ya que resulta claro que el consumidor puede tomar la iniciativa contractual, sea ésta o no oferta de contrato, quedando el supuesto igualmente sometido a la regulación legal. Piénsese, por ejemplo, en el caso en que el consumidor solicita a un empresario un bien conforme a sus especifica-

13 En tales casos, resultarán de aplicación concurrente tanto la LCGC (vid. también el RD 1906/1999, pendiente de modificación, tal y como se anuncia en la disp. final $5^{\text {a }}$ LSSI), como la propia LGDCU en materia de cláusulas abusivas. 
ciones o claramente personalizado [cfr. art. 102.b) LOCM]. Así, quedan sometidos al ámbito de aplicación de la regulación aquellos contratos celebrados a partir de la mera promoción publicitaria por parte del empresario (invitatio ad offerendum en sentido técnico), siempre que éste cuente con un sistema de contratación a distancia. Dicho de otro modo, la existencia de dicho sistema no supone necesariamente que la oferta de contrato, en sentido técnico, corresponda al empresario. Tómese como ejemplo el supuesto en el que un consumidor recibe un catálogo publicitario donde se facilita un número de teléfono para realizar pedidos "a distancia». Si el catálogo publicitario no reúne los requisitos de una oferta de contrato, se trataría de una mera «invitatio ad offerendum», pudiendo corresponder al consumidor la posición de oferente.

Como es sabido, la propuesta del empresario o proveedor sólo constituirá verdadera oferta de contrato si reúne los requisitos de ésta, a saber: (i) la identidad del oferente; (ii) la intención de vincularse si recae aceptación; y (iii) contenido suficientemente preciso. Si es la propuesta del consumidor la que reúne los requisitos de la oferta, corresponderá al empresario la posición de aceptante. De hecho, la regulación no condiciona las manifestaciones de voluntad de las partes más que en el sentido de exigir que la del consumidor sea expresa o explícita, pudiendo consistir la del empresario en la confirmación de recepción del pedido del consumidor o incluso en la ejecución de éste (aceptación por actos concluyentes).

Sentado lo anterior, ha de distinguirse entre oferta de contrato e información previa exigible, ya que el significado de esta última es el de permitir que el consumidor tome una decisión razonada. De manera que se presenta perfectamente compatible con la regulación sobre contratos a distancia la promoción de contratos mediante información publicitaria que contenga tan sólo alguno de los datos exigidos, siempre que el empresario cuente con un sistema organizado a distancia y, antes de celebrarse el contrato, el consumidor disponga de todos ellos. Si el consumidor no dispone de todos ellos antes de celebrar el contrato, el proveedor incumple el deber de información previa.

Ese incumplimiento tan sólo lleva aparejada una sanción administrativa [cfr. Arts. 49.2.b) y 51 LGDCU]. De modo que si, por ejemplo, el empresario no informa al consumidor de todos los datos a que se refiere el artículo 97 LGDCU, pero sí de los elementos esenciales del contrato, éste se entenderá perfeccionado con la aceptación del consumidor, sin perjuicio de la citada sanción administrativa. 
B) Contenido de la información previa exigible. En función de los medios de promoción utilizados, existen algunas informaciones que son previas al inicio del procedimiento de contratación. Se trata de las informaciones exigidas en materia de contratos electrónicos, de manera que el consumidor ha de conocer los pasos técnicos que deben darse para celebrar el contrato o para corregir los errores de introducción de datos; también ha de saber si el prestador de servicios va a registrar o no el contrato celebrado y, finalmente, la lengua o lenguas en las que podrá celebrarse el mismo (cfr. art. 27 LSSI).

Por otra parte, el artículo 97.1.a) LGDCU exige que se informe al consumidor del coste de utilización de la técnica de comunicación cuando se calcule sobre una base distinta de la tarifa básica. Es decir, deberá informarse del importe cuando éste no sea el ordinario (por ejemplo, las llamadas a las líneas «902», respecto de las que debe informarse con carácter previo del coste de la llamada).

Aparte de estas informaciones, el artículo 97.2 LGDCU dispone que la información a que se refiere el apartado $1^{\circ}$ de dicho artículo ha de presentarse: (i) de manera que la finalidad comercial sea indudable; (ii) de modo claro, comprensible e inequívoco; y (iii) respetando los principios de la buena fe en materia de transacciones comerciales, así como la normativa relativa a incapaces de contratar.

Vista la presentación que ha de revestir la información a que obliga el artículo 97 LGDCU, corresponde exponer el contenido de la misma. El artículo 97 no logra cabalmente el objetivo de no incurrir en reiteraciones innecesarias, ya que si bien remite al artículo 60 que, entre las disposiciones generales aplicables a los contratos con consumidores, se refiere a la información previa, luego contiene datos duplicados. Los datos que el empresario debe suministrar al consumidor en dicha información previa constituyen los elementos esenciales del contrato, en esencia: (i) la identidad del empresario y domicilio completo; (ii) las características esenciales del bien o del servicio; y (iii) el precio y otros gastos.

Como se ha expuesto anteriormente, si el empresario se dirige al consumidor precisando estos datos, con intención de quedar vinculado en caso de recaer aceptación, se estaría en presencia de una genuina oferta de contrato que, una vez aceptada, daría lugar al mismo. Pero si el empresario no informa del resto de los extremos a que las normas se refieren, ese incumplimiento sería objeto de sanción administrativa.

El resto de los datos, que no son esenciales para el perfeccionamiento del contrato, son: (i) la forma de pago y de entrega o de eje- 
cución del contrato [art. 97.1 g) LGDCU], con expresión, en su caso, de la duración mínima del contrato para el supuesto de contratos de suministro [art. 97.1 e) LGDCU] y de la concreción de las circunstancias y condiciones de los denominados suministros de sustitución [art. $97.1 \mathrm{f}$ ) LGDCU]; (ii) plazo de vigencia de la oferta [art. 97.1 d) LGDCU]; (iii) existencia del derecho de desistimiento, así como de los supuestos en los que se excluye [art. 97.1 d) in fine LGDCU]; y (iv) si el empresario o proveedor dispone o está adherido a algún procedimiento extrajudicial de solución de conflictos [art. 97.1 h) LGDCU].

\subsection{Manifestación del consentimiento del consumidor}

A la vista de la jurisprudencia del TS en relación con las posibles manifestaciones del consentimiento (básicamente, expreso o por actos concluyentes $)^{14}$ y con el reconocimiento excepcional de valor al silencio en materia contractual ${ }^{15}$, podremos convenir que el apartado primero del artículo 99.1 LGDCU, cuando establece que en ningún caso la «falta de respuesta a la oferta de contratación a distancia podrá considerarse como aceptación de ésta», no supone una gran innovación. Efectivamente, parece claro que si no hay respuesta, no hay consentimiento y tampoco contrato. Obsérvese que esta disposición cobra sentido especialmente cuando el empresario o proveedor ocupa la posición de oferente, aunque igualmente puede entenderse que se emplea el término "oferta» en sentido comercial y no técnico.

En todo caso, el legislador quiere dejar sentado que en los contratos a distancia con consumidores, el silencio de éstos carece total y absolutamente de valor jurídico, de manera que cualquier previsión en sentido contrario (por ejemplo «en caso de falta de respuesta por su parte en «X» días, se considerará que acepta nuestra oferta») será nula. Más aún, podría incluso considerarse como publicidad engañosa.

Por otra parte, el apartado segundo del artículo 99.2 LGDCU establece que si «el empresario, sin aceptación explícita del consumidor y usuario destinatario de la oferta, le suministrase el bien o servicio ofertado, se aplicará lo dispuesto en el artículo siguiente». Es decir, sin aceptación explícita del consumidor, no sólo no hay contrato a distancia, sino que además se incurre en la prohibición de los denominados suministros o envíos no solicitados.

${ }^{14}$ Vid., entre otras, STS de 5 julio 1960 [RJ 1960, 3223].

15 Vid., entre otras, STS de 17 noviembre 1995 [RJ 1995, 8734]. 
Parece claro, en primer lugar, que la referencia legal a la aceptación explícita y a la necesidad de consentimiento expreso no pretende excluir la posibilidad de que la aceptación del consumidor pueda manifestarse a través de cualquier forma adaptada a los medios de comunicación empleados. En segundo lugar, la aceptación del consumidor ha de ser necesariamente explícita respecto de la voluntad de contratar, en el sentido de que cualquiera que sea su actuación habrá de deducirse directamente de ella la intención contractual. Y, en tercer lugar, habrá de recaer sobre el empresario la prueba del consentimiento del consumidor.

Hasta aquí se ha tenido en cuenta el supuesto en que el empresario ocupa la posición de oferente, debiendo ser la aceptación del consumidor explícita en los términos expuestos (para evitar incurrir en la prohibición de suministros no solicitados). Teniendo en cuenta que el consumidor puede perfectamente ocupar la posición de oferente, en tal caso su manifestación de voluntad deberá ser expresa. Este aspecto no está literalmente previsto en la LGDCU, aunque bien pudiera deducirse del título del artículo 99 LGDCU — «necesidad de consentimiento expreso»- y, en todo caso, de la Directiva comunitaria sobre la materia (cfr. art. 9 Dir. 97/7).

\subsection{Suministro de bienes y servicios no solicitados}

Se prevé que el consumidor manifieste su consentimiento de forma expresa o explícita, pues en caso contrario, podría considerarse que se está ante un supuesto prohibido de suministros no solicitados. Por suministros no solicitados ha de entenderse la práctica comercial consistente en remitir al consumidor un bien o prestar algún servicio, sin que él los haya solicitado, con la intención de que pague su precio por falta de tiempo o de ánimo para decidir lo contrario.

En relación con esta práctica prohibida por el artículo 100 LGD$\mathrm{CU}$, titulado "prohibición de envíos no solicitados» ${ }^{16}$, merecen destacarse algunos aspectos. En primer lugar, resulta preciso a los efectos de entender el supuesto como prohibido que no exista consentimiento expreso o explícito del consumidor y anterior al suministro. Por supuesto, el consentimiento no ha de ser necesariamente un consentimiento dirigido a la celebración de un contrato; así, no se consideraría prohibido, por ejemplo, el envío que siga a una

${ }^{16}$ Un estudio de Derecho comparado: ARROYO, A., Los contratos a distancia, op. cit., pp. 269 y ss. 
solicitud del consumidor para probar el bien, reservándose la decisión negocial para después. En segundo lugar, resulta preciso, a los efectos de la prohibición, que del suministro se derive directa o indirectamente una petición de pago; de manera que no estarían prohibidas ni las muestras comerciales ni los suministros gratuitos. Y, en fin, la sanción civil prevista en la LGDCU ha de considerarse como una adquisición de la propiedad o atribución a título gratuito por Ley, ya que el consumidor puede quedarse con el bien o aprovechar el servicio como si de un regalo se tratase. Junto con la sanción civil, la infracción de la prohibición dará lugar a la correspondiente sanción administrativa.

Por otra parte, puesto que la Ley atribuye gratuitamente el bien no solicitado al consumidor, parece admisible que éste renuncie «a posteriori» a ese derecho (art. 6.2 CC) y decida devolver el bien (nótese que este supuesto sólo se adecua a los envíos de bienes y no a la prestación de servicios, irrestituibles en sí mismos). En tal caso, los gastos de devolución deberían ser sufragados por el empresario. Y además el consumidor «no deberá indemnizar por los daños o deméritos sufridos por el producto» (art. 100.1 LGDCU).

Junto con el supuesto prohibido, el artículo 100.2 LGDCU ha regulado los suministros por error en el párrafo tercero, según el cual lo dispuesto para los envíos no solicitados no será de aplicación «cuando quede claramente de manifiesto al consumidor y usuario que el envío no solicitado se debía a un error, correspondiendo al empresario la carga de la prueba». En tal caso «el consumidor y usuario tendrá derecho a ser indemnizado por los gastos y por los daños y perjuicios que se le hubiesen causado» ${ }^{17}$.

\section{Especialidades en la ejecución del contrato}

En la LGDCU se contienen algunas disposiciones que tienen incidencia en la ejecución del contrato y representan, por tanto, especialidades en este tipo de contratación. Estas especialidades permiten distinguir dos fases en la ejecución de todo contrato a distancia: la primera de ellas relativa a la información que el consumidor ha de

17 Obsérvese que la Directiva trató del «error en el envío» en las propuestas anteriores al texto definitivo, pero no en el texto comunitario final. Cabe considerar que el legislador español, al igual que cualquier otro legislador nacional [cfr. BGB § 241a Unbestellte Leistungen, en concreto párrafo (2)], tienen libertad para excluir de la prohibición a los envíos manifiestamente erróneos, ya que entender los mismos como prohibidos es claramente desproporcionado. 
disponer por escrito o en soporte duradero (información vinculada a la ejecución y distinta de la información previa); y una segunda, relativa a la ejecución propiamente dicha (plazo de ejecución, especialidades en ésta y pago mediante tarjeta).

\subsection{Constancia escrita o en soporte duradero de la información}

Aparte del deber de información previa, se exige que el proveedor informe de determinados extremos por escrito o en soporte duradero, a más tardar a la ejecución del contrato. Esta información escrita se distingue de la información previa en cuanto a la forma en que ha de ser facilitada (ya que la información previa puede ser facilitada en cualquier forma) y en cuanto al contenido, ya que se persigue que el consumidor tenga constancia de los términos de su compromiso y conozca otros datos de interés para él.

En cuanto a la forma se refiere, la información deberá facilitarse por «escrito o, salvo oposición expresa del consumidor y usuario, en cualquier otro soporte duradero adecuado a la técnica de comunicación a distancia utilizada» (art. 98.2 LGDCU). Si bien la Ley no dice qué ha de entenderse por "soporte duradero», puede encontrarse una definición, en nuestro ordenamiento, en el artículo 3.3 del controvertido RD 1906/1999. Igualmente puede encontrarse una definición, en el ámbito comunitario, en la Directiva 2002/65, relativa a la comercialización a distancia de servicios financieros, siendo esta última más correcta [cfr. art. 2 f) de dicha Directiva].

En cuanto al contenido, el artículo 98 LGDCU dispone que «antes de la ejecución del contrato deberá facilitarse al consumidor y usuario, en la lengua utilizada en la propuesta de contratación o, en su caso, en la lengua elegida para la contratación» los datos que allí se especifican, entre los que están en primer lugar la información prevista en el artículo 97 LGDCU.

La primera de las menciones adicionales del artículo 98 LGDCU se refiere a la dirección del establecimiento del empresario donde el consumidor pueda presentar sus reclamaciones [art. 98.1.b) LGDCU]. Otra de las menciones se refiere a la información relativa a los servicios de asistencia técnica u otros servicios postventa y a las garantías comerciales existentes [art. 98.1 c) LGDCU]. Por último, en caso de celebración de un contrato de duración indeterminada o de duración superior a un año, deberá informarse de las condiciones de «denuncia» del contrato [art. 98.1.d) LGDCU]. 
En todo caso, esta información escrita o en soporte duradero es de importancia decisiva para el consumidor porque si el proveedor no la facilita, el consumidor dispone de una ampliación del plazo para ejercer el derecho de desistimiento, que es el principal de los derechos atribuidos al mismo (vid. art. 71.3 LGDCU). A esta relevante sanción civil se le une la correspondiente sanción administrativa.

Por otra parte, ha de recordarse que ni el deber de información previa ni el de información escrita o en soporte duradero resultan de aplicación a los supuestos excluidos parcialmente del ámbito. Junto a esos supuestos tampoco será de aplicación a «los servicios cuya ejecución se realice utilizando una técnica de comunicación a distancia que se presten de una sola vez, cuya facturación sea efectuada por el operador de la técnica de comunicación»; aunque, en tal caso, el consumidor «deberá estar en condiciones de conocer la dirección geográfica del establecimiento del proveedor donde pueda presentar sus reclamaciones» (art. 98.3 LGDCU).

\subsection{Entrega y prestación del servicio}

El capítulo IV del Título dedicado a los contratos a distancia se titula "ejecución del contrato" y recoge varias normas referidas también a dicha fase. En el artículo 103 LGDCU se dispone que "salvo que las partes hayan acordado otra cosa, el empresario deberá ejecutar el pedido a más tardar en el plazo de treinta días a partir del día siguiente a aquel en que el consumidor haya comunicado su consentimiento para contratar».

Como puede observarse no existe un plazo legal máximo irrenunciable, así como tampoco plantea problemas la posible fijación de un plazo superior en condiciones generales o no negociadas individualmente. En este sentido, no debe olvidarse que tendrá la consideración de cláusula abusiva «la consignación de fechas de entrega meramente indicativas condicionadas a la voluntad del empresario» (art. 85.8 LGDCU). Otra referencia a la indeterminación del plazo se halla, aunque de forma más general, en el artículo 85. 1 LGDCU, según el cual, tienen el carácter de abusivas las cláusulas «que reserven al empresario que contrata con el consumidor un plazo excesivamente largo o insuficientemente determinado para aceptar o rechazar una oferta contractual o satisfacer la prestación debida...». Este tipo de cláusulas serían «nulas de pleno derecho y se tendrán por no puestas» (cfr. art. 83.1 LGDCU). 
El plazo de treinta días se computará de conformidad con el artículo 5 CC, iniciándose el cómputo a partir del día siguiente a aquel en que el consumidor haya comunicado su pedido, de manera que, al menos, se proporciona al consumidor una fecha cierta a partir de la cual se calculará el plazo.

La Ley se ocupa de la posible indisponibilidad del bien o del servicio. Así, el artículo 104 impone al empresario el deber de informar al consumidor, en caso de indisponibilidad del bien o del servicio solicitado, debiendo devolver "cuanto antes y, en cualquier caso, en un plazo de treinta días como máximo, las sumas que haya abonado».

Este precepto resulta criticable, ya que el legislador se limitó a copiar el artículo 7.2 de la Directiva 97/7 sin valorar la conveniencia de introducir semejante norma en nuestro ordenamiento. Así, no cabe ignorar que si el contrato se hubiera perfeccionado con la solicitud del consumidor, se estaría en presencia de un incumplimiento de la obligación de entrega o prestación del servicio por indisponibilidad. La única medida adoptada para contrarrestar los inconvenientes que se plantean consiste en haber previsto, para el caso de que el empresario no realice el abono de las sumas ya pagadas por el consumidor, que éste "podrá reclamar que se le pague el doble de la suma adeudada, sin perjuicio de su derecho de ser indemnizado por los daños y perjuicios sufridos en lo que excedan de dicha cantidad» (art. 104, $2^{\circ}$ párrafo LGDCU).

En el artículo 105 se ha previsto, por otra parte, la entrega de un bien o la prestación de un servicio de calidad y precio equivalentes, ante la indisponibilidad del que fue solicitado. Ahora bien, en principio, este suministro de sustitución sólo podrá tener lugar cuando se haya informado expresamente de tal posibilidad al consumidor y para el supuesto de indisponibilidad. Es decir, el «suministro de sustitución» es subsidiario en caso de no hallarse disponible el bien o servicio. Se trataría de una "subsanación» del incumplimiento a través del nuevo suministro, que ha de ser valorada teniendo en cuenta los intereses encontrados. Parece razonable considerar que debería haberse previsto expresamente que al consumidor le corresponde optar por el cumplimiento del contrato con un suministro de sustitución. Lo que sí se ha previsto es que el precio no ha de variar y la calidad ha de ser igual o superior, además de que el consumidor podrá igualmente ejercitar el derecho de desistimiento, sin que en tal caso puedan imputarse al consumidor «los costes directos de devolución» del bien que serán de cuenta del empresario. 


\subsection{Pago mediante tarjeta}

El artículo 106 LGDCU se destina a la posible utilización fraudulenta de una tarjeta de pago. La finalidad de la norma es la de dar respuesta al problema derivado del uso de una tarjeta por un tenedor distinto del titular legítimo en la realización de contratos a distancia. En estos contratos, al no existir presencia simultánea de las partes, ocurre que en el momento del pago mediante tarjeta no hay firma del titular, ni identificación a través del DNI o empleo del código NIP, ni siquiera presentación material de la tarjeta, ya que basta con facilitar el número y la fecha de caducidad de la tarjeta. Estos dos últimos datos implican que incluso no es preciso ser tenedor de la tarjeta, sino que es suficiente disponer de ellos para poder utilizarla fraudulentamente. Desde luego, el supuesto amparado será tanto el de la conducta fraudulenta o abusiva de un tercero o del propio empresario, como los supuestos de error.

La norma ha previsto que si se utiliza fraudulenta o indebidamente el "número de una tarjeta de pago», el titular puede exigir la inmediata anulación del cargo. No se trata de una revocación de la orden de pago del titular, sino que ésta no existió; pues si hubiera existido, entonces la «anulación» será indebida e implica que el titular queda obligado frente al empresario al «resarcimiento de los daños y perjuicios ocasionados como consecuencia de dicha anulación» (art. 106.2 LGDCU). En definitiva, el artículo 106 pretende trasladar al empresario el perjuicio del consumidor por la utilización fraudulenta o indebida del número de su tarjeta de pago.

Si se dan los presupuestos previstos en el artículo 106.1 LGDCU y el titular procede a la debida anulación del cargo, ésta se ejecutará mediante las «anotaciones de adeudo y reabono en las cuentas del empresario y del consumidor». Así, no se "anula» propiamente el cargo ya realizado, sino que se restituye el saldo a través de las correspondientes anotaciones en las cuentas de las partes implicadas.

El artículo 106 omite cualquier referencia a la incidencia que la anulación del cargo pueda tener en relación con el contrato a distancia. Lógicamente, si el contratante que efectuó el pago anulado incumple el contrato, al menos incurrirá en mora si decide pagar después. 


\section{Derecho de desistimiento}

\subsection{Reconocimiento legal del «derecho de desistimiento» para los contratos a distancia. Naturaleza}

El principal derecho atribuido al consumidor en este tipo de contratación es el derecho de desistimiento, institución a la que, como es sabido, se ha recurrido en otras ocasiones en materia de protección de consumidore ${ }^{18}$. El fundamento de política legislativa a que obedece la atribución de este derecho en los contratos a distancia es, sin duda, que puesto que el consumidor contrae un compromiso «a ciegas», se le permite una segunda oportunidad para decidir el mantenimiento de dicho compromiso o bien arrepentirse sin justificar porqué. El derecho de desistimiento permite de este modo contrarrestar la inicial desventaja contractual del consumidor.

Originariamente, el reconocimiento legal del derecho de desistimiento se concretó en el artículo 44 LOCM que, como se expuso al inicio, hoy permanecería vigente en la LOCM para «las relaciones empresariales», como consecuencia inesperada de la duplicación provocada a partir del Real Decreto Legislativo 1/2007. En todo caso, en lo que al derecho de desistimiento para los contratos a distancia celebrados con consumidores se refiere, las normas que han de tenerse en consideración ahora son los artículos 101 y 102 de la LGDCU, específicos para estos contratos, complementadas (art. 68.3 LGDCU) con lo previsto en el capítulo II, del título I del libro II (arts. 68 y ss. LGDCU), en el que se contiene la regulación completa del derecho para todos los contratos en los que se atribuya.

En la regulación originaria el principal problema que se planteaba en relación con este derecho no quedaba resuelto expresamente por la LOCM. Se trataba de averiguar si el consentimiento del consumidor prestado en condiciones precarias era o no suficiente para producir el perfeccionamiento del contrato. Dicho de otro modo, si el derecho de

18 Entre otras Directivas comunitarias, que han recibido correspondencia en nuestro ordenamiento, cabe citar: Dir. 85/577/CEE sobre contratos celebrados fuera de los establecimientos mercantiles; art. 6 ss. Dir. 2002/65/CE, sobre servicios financieros a distancia; art. 35 Dir. 2002/83/CE, sobre seguros de vida; arts. 14 ss. Dir. 2008/48/CE, sobre crédito al consumo; arts. 6 ss. Dir. 2008/122/CE, sobre aprovechamiento por turno de bienes inmuebles. En la doctrina europea, se ha venido poniendo de manifiesto la necesidad de una "armonización» mayor respecto de los derechos de desistimiento en el Derecho comunitario: LOOS, M., "The case for a uniform and efficient right of withdrawal from consumer contracts in European Contract Law», Zeitschrift für Europäisches Privatrecht, 1/2007, pp. 5 a 36. 
desistimiento que se atribuía al consumidor implicaba el perfeccionamiento progresivo del contrato o si, por el contrario, el contrato se perfeccionaba como cualquier otro - por el intercambio de las declaraciones de voluntad- y el desistimiento suponía la extinción de un contrato ya perfeccionado. Y ello sobre todo a la vista del artículo 1256 del Código civil que dispone que «la validez y el cumplimiento de los contratos no puede dejarse al arbitrio de uno de los contratantes». En todo caso, apreciada la totalidad del régimen legal [cfr., entre otros, el art. 44.1 «desistir del contrato»; y el artículo 47.1 a), que referido a «los datos de identificación del contrato y de los contratantes»], se consideraba ${ }^{19}$ que el contrato a distancia se perfeccionaba por el intercambio de las declaraciones de voluntad de las partes y el derecho de desistimiento se atribuía al consumidor respecto de un contrato ya perfeccionado. La Ley permitía excepcionalmente a una de las partes de la relación contractual -el consumidor- desvincularse libre y unilateralmente del contrato durante un plazo en atención a las circunstancias en que aquél se celebró. Pero es que además este derecho de desistimiento se distingue nítidamente de otras figuras como puedan ser la resolución por incumplimiento (ya que aquél es ejercitable libremente), o la denuncia unilateral, propia de los contratos de tracto sucesivo, y cuyo ejercicio deja en pie los efectos ya producidos.

El actual artículo 68 LGDCU, dedicado al «contenido y régimen del derecho de desistimiento", no plantea ya ninguna duda al disponer que el «derecho de desistimiento de un contrato es la facultad del consumidor y usuario de dejar sin efecto el contrato celebrado, notificándoselo así a la otra parte contratante en el plazo establecido para el ejercicio de ese derecho, sin necesidad de justificar su decisión y sin penalización de ninguna clase». Se establece un plazo «general» de siete días hábiles para desistir del contrato sin penalización alguna y sin indicación de los motivos (art. 70 LGDCU). Se trata por tanto de un derecho de ejercicio libre, sin necesidad de justificar causa alguna («ad nutum»), como libre es la forma en que puede ejercitarse (art. $70 \mathrm{LGDCU}^{20}$ ). Así mismo, el ejercicio del derecho es gratuito, en cuanto que no podrá implicar la imposición de penalidad alguna (art. 73 LGDCU), salvo satisfacer, en su caso, los gastos directos de devolución (art. 101 LGDCU.

En resumen, el derecho de desistimiento atribuido al consumidor es un derecho: (i) legal (art. 68 LGDCU) o, en su caso, convencional-

19 ARROYO, A., Los contratos a distancia, op. cit., pp. 346 y ss.

20 Vid. SAP Madrid 1 marzo 2005 [JUR 2005, 84465], aunque referida al art. 44.2 LOCM. 
mente reconocido (art. $102 \mathrm{LGDCU}$ ab initio «salvo pacto en contrario»); (ii) unilateral, ya que se atribuye al consumidor; (iii) de ejercicio discrecional o libre - «ad nutum»—, como se ha señalado (iv) no sujeto a formalidad alguna (art. 70 LGDCU); (v) de ejercicio gratuito (no cabe imposición de penalidad alguna vinculada al ejercicio, art. 73 LGDCU); (vi) con efectos restitutorios, situando a las partes como si el contrato no hubiera tenido lugar; y (vii) sometido a un plazo de ejercicio (art. 71 LGDCU).

En relación con el plazo de ejercicio ha de mencionarse que la LGDCU ha previsto una sanción para el caso de incumplimiento del deber de información recogido en el artículo 69.1 LGDCU, de manera que dicho plazo se amplía hasta tres meses (cfr. art. 71.3 LGDCU). Para este supuesto de ampliación no se está ante otra institución distinta al "desistimiento» propio de los contratos a distancia, de hecho la LGDCU sigue empleando el mismo término de "desistimiento». En realidad, se trata de un supuesto de ampliación del plazo para desistir, en atención al incumplimiento por parte del empresario, no de la prestación principal que deriva del contrato, sino del deber de información escrita o en soporte duradero a que se refieren los artículos 97 y 98 LGDCU. De manera que cabe entender que la ampliación del plazo es una sanción por este incumplimiento del deber de informar, pero el derecho atribuido al consumidor sigue siendo ejercitable libremente, ad nutum. El consumidor puede desistir igualmente durante ese período de tres meses sin justificar la causa. Téngase en cuenta que otra interpretación sería contraria a la finalidad de la normativa y, lo más importante, no cumpliría el mínimo impuesto por la Directiva 97/7 sobre la materia, que en este punto es absolutamente clara (art. 6 Dir. 97/7). No se olvide que las normas de transposición de los Estados miembros no pueden, en ningún caso, establecer una menor protección para el consumidor.

\subsection{Régimen jurídico}

El derecho de «desistimiento» se atribuye al consumidor respecto de todo contrato a distancia sometido a la aplicación de la regulación española (arts. 92 y ss. LGDCU), siempre que no esté excluido además de la aplicación de dicho derecho (cfr. art. 102 LGDCU). Reténgase que tan relevante es el artículo 93 como el 102 a los efectos de considerar en qué casos no se reconoce el derecho; relevancia que se ha puesto de manifiesto en el "Asunto easyCar», que se analiza a continuación (infra III.1). 
Así mismo, puede ocurrir que transcurra el plazo de ejercicio del derecho de desistimiento y el consumidor no lo haya ejercitado. En tal caso, el consumidor podrá evidentemente ejercitar cualesquiera otros derechos que le correspondan con carácter general, aun cuando la LGDCU sólo cite expresamente «las acciones de nulidad o resolución del contrato cuando procedan conforme a derecho» (art. 78 LGDCU).

A) Plazo de ejercicio: duración y cómputo. Se establece un plazo general de siete días «hábiles» para desistir del contrato (art. 71 LGDCU), distinguiendo para el inicio del cómputo del plazo según el contrato recaiga sobre bienes o sobre servicios y, previendo un régimen distinto, según se haya cumplido o no el deber de información.

Así, cumplido el deber de información, el plazo comenzará a contarse a partir del día de la recepción de los bienes y para la prestación de servicios, a partir del día de la celebración del contrato (art. 71.2 LGDCU).

En el caso de que el empresario haya incumplido con el deber previsto en el artículo 69.1 LGDCU, el plazo de ejercicio del derecho será de tres meses contados igualmente desde la recepción (aunque el art. 71.3 LGDCU se refiera al día en que se «entregó el bien»); y para la prestación de servicios, desde la celebración del contrato. Si dentro de los tres meses señalados, el empresario cumpliera dicho deber, el plazo de siete días antes referido comenzaría a partir de ese momento. En consecuencia, se ha previsto una sanción civil con efectos en el plazo que se prolonga hasta un máximo de tres meses, que puede ser interrumpido - en realidad, acortado- por el cumplimiento del citado deber de información, para la entrada en juego entonces del plazo de siete días. Obsérvese que en la regulación contenida en la LOCM se preveía para el caso de incumplimiento del deber de información que no pudiera exigirse al consumidor que se hiciera cargo de los costes de devolución (art. 44.5, pensado claramente para el supuesto de bienes) y esta norma parece que no ha recibido correspondencia en la actual LGDCU.

El plazo de siete días puede ser ampliado, pero no reducido («plazo mínimo» dice el artículo 71.1 LGDCU) y la determinación de qué días tienen la consideración de «hábiles» se hará conforme a la ley del lugar donde se ha entregado el bien o prestado el servicio. A este respecto debe puntualizarse que hubiera sido más correcto el empleo de los términos «días laborables» o, tal vez, otra opción más conve- 
niente, en atención a las diferencias en el calendario de una Comunidad Autónoma a otra y de un país a otro, hubiera sido prever un plazo superior de días naturales (14 días, por ejemplo).

El régimen establecido supone algo más y es que, aunque el empresario no cumpla con el deber de información escrita o en soporte duradero, el derecho de desistimiento decae por el transcurso del plazo sin ser ejercitado.

Por otra parte, cabe apuntar que la distinción entre bienes y servicios se justifica porque los bienes pueden ser restituidos sin perjuicio para el empresario (pueden ser «devueltos»), mientras que los servicios son irrestituibles «in natura» una vez prestados. En todo caso, resulta claro que el legislador no ha tenido en cuenta que algunos servicios - de conexión a internet, por ejemplo- deberían recibir un tratamiento diferenciado. Sobre todo, a la vista de la regulación sobre contratación a distancia de servicios financieros en el ámbito comunitario, en la que se prevé el ejercicio de un derecho de desistimiento, si bien con la repercusión sobre el consumidor de un importe proporcional al servicio realmente prestado al momento de ejercitarse el derecho.

B) Forma. Según el artículo 70 LGDCU, «el ejercicio del derecho de desistimiento no estará sujeto a formalidad alguna, bastando que se acredite en cualquier forma admitida en Derecho». Cualquier pacto que exija al consumidor el ejercicio del derecho de una forma determinada es nulo. Lo relevante es que el consumidor esté en condiciones de acreditar el ejercicio y que fue tempestivo. El ejercicio podrá ser expreso o por actos concluyentes, mediante la devolución del bien por ejemplo, o de la petición de anulación del cargo de la tarjeta de pago, o a través del "documento de desistimiento», siendo este último especialmente indicado a tal fin.

C) Excepciones al derecho de desistimiento. Como es sabido, con la regulación del derecho de desistimiento se persigue que de su ejercicio no se derive ninguna consecuencia negativa para el consumidor, ya que su efecto principal es el de la obligación de restitución de las prestaciones, situando a las partes como si el contrato no hubiera tenido lugar. Este último dato es el que explica que algunos supuestos queden excluidos del derecho de desistimiento, como ocurre con los supuestos en los que los bienes pierdan su valor de cambio una vez celebrado el contrato; o como ocurre con los supuestos en los que los bienes se incorporen definitivamente al patrimonio del consumidor, siendo entonces irrestituibles. 
Así, el artículo 102 de la Ley ha previsto que, salvo pacto en contrario, el derecho de desistimiento no será de aplicación, en primer lugar, a los contratos en los que el precio esté sujeto a fluctuaciones de coeficientes del mercado financiero que el empresario no pueda controlar. Se persigue evitar que el derecho pueda ser ejercitado para especular en perjuicio del empresario.

En segundo lugar, el artículo se refiere a los bienes confeccionados conforme a las especificaciones del consumidor y a los que, por su naturaleza, no pueden ser devueltos o puedan deteriorarse o caducar con rapidez. Recuérdese que gran parte de los bienes perecederos o no duraderos ya están excluidos parcialmente de la regulación, aunque parece que, en todo caso, el fundamento de la excepción está en la ineptitud del bien para ser reintroducido en el mercado si fuesen devueltos por el consumidor.

El tercer supuesto citado por el artículo 102 se refiere a objetos que puedan ser, una vez desprecintados, reproducidos o copiados con carácter inmediato. El fundamento es obvio ya que el consumo inmediato - y aquí lo hay pues el consumidor puede incorporar a su patrimonio el bien copiándolo- es incompatible en sí con el derecho de desistimiento. Ha de advertirse que en la práctica pueden darse problemas respecto de la prueba acerca de cuándo se procedió al desprecintado del bien, ya que nada impide que viniera así desde el origen.

El último supuesto citado en el artículo 102 se ciñe a los suministros de prensa diaria, publicaciones periódicas y revistas. Estos bienes si se devuelven pierden su valor y este fundamento es compartido con los supuestos de loterías y apuestas que tienen una fecha determinada, citados éstos en apartado f) del mismo artículo.

En el artículo 102. e) LGDCU se hace alusión igualmente a los supuestos de prestación de servicios. Así, se dispone que el consumidor no dispondrá del derecho de desistimiento si el contrato de prestación de servicios ha comenzado, con el acuerdo del consumidor, antes de finalizar el plazo de siete días hábiles. De manera que, en realidad, se atribuye un plazo para desistir antes de la ejecución de la prestación, que dacae tan pronto se inicie ésta, que una vez realizada no puede ser «devuelta» por definición.

D) Efectos. Ejercitado el derecho, cualquiera de las partes podrá exigir la restitución de lo entregado. La LGDCU se ha remitido expresamente a los artículos 1303 y 1308 CC, normas en las que se halla el criterio general aplicable a todo supuesto de restitución por 
decaimiento del título contractual (y pérdida «retroactiva» de la eficacia). En definitiva, se trata de situar a las partes en la situación económica que ocuparían si el contrato no se hubiera celebrado.

En relación con el riesgo de la cosa, para el caso de bienes, desde su entrega al consumidor hasta la devolución, habrá de estarse a lo dispuesto en el artículo 75 LGDCU referido a la «imposibilidad de devolver la prestación por parte del consumidor y usuario», respondiendo únicamente el consumidor de su valor cuando la pérdida le sea imputable.

Finalmente, la Ley establece que en caso de que el precio «haya sido total o parcialmente financiado mediante un crédito concedido al comprador por el empresario contratante o por parte de un tercero, previo acuerdo de éste con el empresario, el ejercicio del derecho de desistimiento implicará al tiempo la resolución del crédito sin penalización alguna para el consumidor y usuario» (art. 79 LGDCU). Se está en presencia de una manifestación de los denominados «contratos vinculados» o «conexos», respecto de los que se autoriza al consumidor a ejercitar frente a quien le concedió el crédito los derechos que le correspondan frente al vendedor, condicionándose tal efecto a la existencia de determinados requisitos entre los que está la existencia de acuerdo entre el tercero y el vendedor para la financiación.

Ahora bien, en el caso de los contratos a distancia, el efecto consiste en que cuando el precio haya sido financiado por un crédito, el desistimiento del contrato financiado implicará «la resolución del crédito sin penalización alguna», siempre que dicho crédito se haya instrumentado mediante un contrato con el propio empresario o con un tercero, previo acuerdo con el empresario. La resolución del contrato de crédito, se haya celebrado con el empresario o con el tercero, proviene de la desaparición sobrevenida de la base del mismo, que es el contrato a distancia.

Finalmente, ha de advertirse que la Directiva 97/7 dispone que cuando el consumidor desiste del contrato y se ha de devolver el producto al proveedor, no puede imputarse otro gasto al mismo que «el coste directo de la devolución» ${ }^{21}$. Sobre este aspecto, conviene advertir que nuestra legislación originaria contenida en la LOCM no preveía ninguna norma expresamente, pero ahora el régimen general del derecho de desistimiento, aplicable también a los contratos a distancia, dispone de forma explícita que el ejercicio del derecho no

${ }^{21}$ Arts. 6.1 y 6.2 Directiva. 
implicará gasto alguno para el consumidor y usuario (art. 73 LGDCU). En relación con este aspecto ha de considerarse la STJCE recaída el 15 de abril de 2010 en el Asunto Handelsgesellschatf Heinrich Heine, que interpreta el artículo 6 de la Directiva en el sentido de considerar que éste se opone a una normativa nacional que permite al proveedor, en un contrato celebrado a distancia, imputar los gastos de envío de los bienes al consumidor en el caso de que éste ejercite el derecho de desistimiento (vid. infra más extensamente III.2).

\section{CONTRATOS A DISTANCIA EN LA JURISPRUDENCIA DEL TJUE (ASUNTOS EASYCAR Y HANDELSGESELLSCHAFT HEINRICH HEINE)}

\section{Exclusión del derecho de desistimiento en los contratos a distancia de alquiler de coches, en tanto que son considerados como "contratos de suministro de servicios de transporte»: el Asunto "easyCar».}

A) Antecedentes: el litigio y la cuestión prejudicial. En el marco de un litigio entre la sociedad inglesa "easyCar Ltd.», dedicada al alquiler de vehículos que presta servicios a través de Internet, y la OFT (Office of Fair Trading), se solicitó al Tribunal correspondiente (High Court of Justice) que se pronunciara sobre la falta de conformidad de los contratos de alquiler de vehículos de «easyCar» con las normas inglesas de incorporación de la Directiva 97/7/CE ${ }^{22}$. La OFT consideraba que los contratos utilizados por la sociedad inglesa eran contrarios a la normativa nacional en tanto que implicaban la pérdida de la reserva realizada por el cliente si desistía sin justificación del contrato concertado a distancia. EasyCar entendía en cambio que los servicios por ella prestados no estaban sujetos a la obligación de reembolso de las cantidades por el consumidor en caso de desistimiento al hallarse comprendidos en la excepción prevista para los «contratos de suministro de servicios de transporte».

Ha de destacarse de los hechos del litigio principal que la OFT había actuado movida por la existencia de varias denuncias de consumidores y clientes de easyCar, así como que en los contratos de la sociedad sólo se reconocía la posibilidad de reembolso en caso de «circunstancias inusuales e imprevisibles», tales como «una enfermedad grave del conductor que le incapacite para conducir», «catás-

\footnotetext{
22 Consumer Protection Distance Selling Regulations 2000.
} 
trofes naturales», así como "actos o restricciones de Gobiernos o de autoridades públicas, guerras, disturbios, conmoción civil o actos de terrorismo».

Pues bien, en el Asunto aquí analizado, el tribunal inglés — High Court of Justice - planteó una cuestión prejudicial al Tribunal de Justicia en la que se preguntaba acerca de si la categoría de contratos de suministros de servicios de transportes incluía los servicios de alquiler de vehículos y, en consecuencia, la exclusión prevista por la Directiva 97/7/CE en el artículo 3.2 resultaba de aplicación a los contratos de easyCar.

A fin de ilustrar el caso, recordando la normativa española, nos planteamos ¿cuál es el régimen español al respecto? Recuérdese que el ámbito de aplicación de la regulación española, en concordancia con la Directiva 97/7/CE, viene delimitado por los requisitos que ha de cumplir todo contrato a distancia, debiendo tener en cuenta las exclusiones totales y parciales expresamente previstas. Las exclusiones totales vienen constituidas por aquellos contratos que no quedan sometidos a la totalidad de la regulación (contratos realizados a través de máquinas automáticas o locales comerciales automatizados, contratos celebrados en subastas - excepto las electrónicas-, servicios financieros, contratos celebrados con los operadores de telecomunicaciones a través de los teléfonos públicos, los celebrados para la construcción de bienes inmuebles).

Junto con las exclusiones totales, la LGDCU recoge dos supuestos a los que no son de aplicación las siguientes normas de protección del consumidor: (i) los artículos 96.1 y 2 relativos a las comunicaciones comerciales; (ii) el artículo 97 destinado a regular la información que se ha de facilitar al consumidor previamente a la celebración del contrato; (iii) el artículo 98 sobre confirmación escrita de la información; (iv) el artículo 101 que regula el derecho de desistimiento; y (v) el artículo 103 que se refiere al plazo de ejecución del contrato.

La exclusión parcial la constituyen los supuestos de contratos sobre bienes de consumo corriente y los contratos de suministro de servicios de alojamiento, transporte, comidas y actividades de recreo. Estas exclusiones, que he denominado parciales, se recogen en el artículo 93.2 LGDCU, titulado «excepciones». Las exclusiones parecen encontrar su justificación en que determinados contratos, vinculados a determinados objetos, merecen tan sólo una protección parcial ya que, principalmente, la naturaleza del objeto sobre el que recaen resulta incompatible con el ejercicio del derecho de desistimiento. 
Se observará, por tanto, que a los dos supuestos de exclusiones parciales no se les aplica - además de otras - la norma protectora por excelencia de este tipo contractual: el derecho de desistimiento.

En el Asunto easyCar la cuestión prejudicial se centra en determinar qué ha de entenderse por servicios de transporte a los efectos del artículo 3, apartado 2, de la Directiva. Evidentemente la interpretación que el Tribunal ofrezca sirve para interpretar el artículo 93.2 LGDCU. En el caso no se discute que los contratos celebrados entre la sociedad easyCar y sus clientes son contratos a distancia a los efectos de la normativa inglesa y de la Directiva, sino que se trata de dilucidar si los servicios de alquiler de vehículos son servicios de transporte a efectos del artículo 3, apartado 2, de la Directiva. Y reténgase que la consecuencia de afirmar lo anterior implica que en dichos servicios no se reconoce el derecho de desistimiento a los clientes, consumidores, de manera que no tendrían derecho a ser reembolsados de los gastos de reserva si así se había previsto contractualmente.

B) La Sentencia «easyCar» de 10 de marzo de 2005. En la sentencia se analizan los trabajos preliminares de la Directiva, llegándose a concluir que no existe en ellos una interpretación del alcance exacto del concepto de "servicios de transporte». Así mismo se pone de manifiesto que la sistemática general de la Directiva evidencia que su finalidad es conseguir que los consumidores gocen de una amplia protección ${ }^{23}$. Esa amplia protección se concreta en derechos como el desistimiento, que es el más relevante de los reconocidos al consumidor. Pero recuérdese que ese derecho no se reconoce de forma absoluta, sino que se prevén excepciones al mismo, algunas de ellas referidas a cuatro sectores de actividad económica "próximos entre sí, entre los que se encuentra el de los servicios de transporte», en términos textuales de la resolución.

La Sentencia aduce que ante la inexistencia de interpretación posible extraída del iter de tramitación o de la sistemática de la propia normativa, ha de acudirse a la jurisprudencia comunitaria reiterada que defiende la determinación del significado y alcance de los términos de conformidad con "el sentido habitual de éstos en el lenguaje corriente, o teniendo en cuenta el contexto en el cual se utilizan y los objetivos perseguidos por la normativa de la que forman parte» ${ }^{24}$. Y,

\footnotetext{
23 § 20 de la STJCE.

24 Sentencias de 19 de octubre de 1995, Hönig, C 128/94, Rec. p. I 3389, apartado 9, y de 27 de enero de 2000, DIR Internacional Film y otros/Comisión, C 164/98 P, Rec. p. I 447, apartado 26.
} 
además, se precisa que cuando dichos términos figuran, como en el asunto principal, en una disposición que constituye una excepción a un principio o, más en concreto, a normas comunitarias encaminadas a proteger a los consumidores, deben, además, interpretarse estrictamente ${ }^{25}$.

Sentado lo anterior, se concluye que la expresión «servicio de transporte» debe entenderse como una categoría de servicios, un sector en suma, esto es, quedan excluidos de la atribución o reconocimiento del derecho de desistimiento los «servicios en el sector de transportes» en general ${ }^{26}$. Esa conclusión se apoya en que el legislador comunitario no empleó el término «contratos de transporte», que en los ordenamientos nacionales suele ceñirse al transporte de pasajeros y mercancías, sino que se empleó de forma deliberada una expresión amplia, que puede englobar todo el conjunto de contratos que regulan los servicios en materia de transportes, de manera que no sólo cubra los transportes de personas o mercancías, sino también los contratos relativos a servicios en materia de transportes, incluidos los que impliquen una actividad que no suponga, en sí misma, el transporte del cliente o de sus bienes, sino que pretenda permitir a éste que lleve a cabo el transporte citado.

C) Conclusiones. La Sentencia declara que el artículo 3.2 de la Directiva 97/7/CE debe interpretarse en el sentido de que el concepto de «contratos de suministro de servicios de transporte» incluye los contratos de suministro de servicios de alquiler. El pronunciamiento es claro al entender que la exclusión se refiere a categorías de servicios por sectores y no por contratos o tipo de contratos (§ 24). Ahí reside la conclusión del Tribunal: considera que del tenor literal del artícu-

25 Sentencias de 18 de enero de 2001, Comisión/España, C 83/99, Rec. p. I 445, apartado 19, y de 13 de diciembre de 2001, Heininger, C 481/99, Rec. p. I 9945, apartado 31.

26 Sobre este pronunciamiento: Walter, B. A., «Autovermietung und Fernabsatz: Der Ausgleich von Unternehmensinteressen und Verbraucherschutz», European Law Reporter, 2005 pp. 203-205; Idot, L.: «Précisions sur les exceptions à la directive sur les contrats à distance», Europe 2005 Mai Comm. n. 179 p. 27; Junker, M., "Fernabsatzrecht und Online-Buchung von Mietwagen», Computer und Recht 2005 p.653-655; Telkamp, M., «Keine Kostenerstattung bei Widerruf von Internet-Automietverträgen», Ecolex 2005 p. 584; Zarka, J. C., „Contrats de locations de voitures conclus à distance et protection des consommateurs, La Semaine juridique - édition générale 2005 II 10059; Adobati, E., «La Corte di Giustizia precisa la portata della protezione dei consumatori nei contratti a distanza di noleggio di autoveicoli conclusi via internet», Diritto comunitario e degli scambi internazionali 2005 pp. 705-706; Ultsch, M. L., «Widerrufbarkeit von Mietwagenbuchungen», Zeitschrift für europäisches Privatrecht, 2006 pp. 173-189. 
lo 3 , apartado 2 , se desprende que todos los contratos relativos a los sectores de alojamiento, transportes, comidas y esparcimiento, con excepción de aquellos que no deban cumplirse en una fecha determinada o durante un período concreto, se hallan comprendidos en la excepción (§ 24). Y en tal sentido habrá de interpretarse el artículo 93.2 de la LGDCU, que regula la materia en nuestro Derecho.

La relevancia de esta Sentencia va más allá de su resultado, pudiendo extraerse conclusiones interesantes respecto del método hermenéutico del Tribunal frente a las normas de protección de los consumidores $^{27}$. Objetivo que queda fuera de estas páginas, en las que sólo se persigue analizar la incidencia para el régimen de los contratos a distancia con las matizaciones que se exponen a continuación.

Sin duda, el Tribunal emplea la metodología interpretativa al uso en la mayoría de los sistemas nacionales, similar a la recogida en el artículo 3.1 del Código Civil, esto es, se consideran en particular, aunque de forma un tanto desordenada: el elemento gramatical, sistemático, histórico (en concreto, el iter de preparación del texto comunitario), sociológico y el criterio teleológico. De forma significativa, se han tenido en cuenta también los diferentes intereses en juego: nótese que el $\S 28$ alude a que las exigencias de la Directiva pueden afectar «desproporcionadamente a los proveedores de determinados sectores», en particular, en el «supuesto de que un servicio haya dado lugar a una reserva y de que ésta última sea anulada por el consumidor poco tiempo antes de la fecha prevista». Y se ha de retener que de la tramitación de la Directiva podía constatarse que la exclusión parcial de estos servicios era la evolución de la fórmula contenida en las primeras propuestas consistentes en «servicios con reserva ${ }^{28}$; término que es traído a colación por el propio Tribunal en el § 28 reproducido — que apoya en este punto lo alegado por la sociedad easyCar-, aunque antes —en el § 20- exponga -incurriendo en cierta descoordinación-que en los trabajos preparatorios de la Directiva no se «aclara» el alcance exacto de «servicios de transportes». Es decir, el Tribunal podría haber traído a co-

${ }^{27}$ CÁMARA LAPUENTE, S., «Tipos contractuales, excepciones sectoriales y metodología hermenéutica del derecho de consumo según la jurisprudencia comunitaria: «easyCar» o el desistimiento en el alquiler a distancia de vehículos (Sentencia TJCE de 10 de marzo de 2005, Asunto C-336/03)», RFDUG, 9/2006, pp. 375 a 405.

28 En las primeras propuestas de la Directiva el supuesto osciló desde una exclusión total (Propuesta de 1992) hasta una supresión del derecho de desistimiento (Propuesta de 1993), para llegar al régimen intermedio final a partir de la Posición Común de 1995: ARROYO, A., Los contratos a distancia, op. cit., pp. 210 y 211. 
lación los trabajos preparatorios de la Directiva para defender que los «servicios de transporte» se enmarcaban en la evolución posterior de los inicialmente llamados «servicios con reserva», pues viene a llegar a esta conclusión (§ 28 y 29) pero por otra vía más compleja $(\S \S 22 \text { a } 27)^{29}$.

Por otra parte, se observa que la Sentencia apela al «sentido habitual» de los términos "en el lenguaje corriente» (§ 21), a la consideración de los servicios de transporte como enmarcados en una «excepción sectorial» (sector de los transportes, cfr. § 22). En ese contexto, se apunta que el legislador comunitario no empleó el término «contratos de transporte» (§§ 23 y 24), sino "contratos de suministro de servicios de transporte» - y ello en todas las versiones lingüísticas (§ 25)—, que es decididamente una expresión más amplia. También en este punto los razonamientos del Tribunal discurren por senda llena de vericuetos para terminar por sostener en el § 29 que es «forzoso reconocer que las empresas de alquiler ejercen una actividad que el legislador ha pretendido proteger» contra los inconvenientes de cancelaciones de reservas «poco tiempo antes de la fecha prevista para la prestación» del servicio.

Ha de matizarse, en todo caso, que no se trata tanto de la consideración predominante de los intereses de los proveedores por la Sentencia, como de la consideración de esos intereses en contraposición con los de los consumidores en la base de la exclusión prevista ya por la Directiva. Es decir, el derecho de desistimiento se reconoce siempre que el empresario pueda «reintroducir» lo que ofreció en el mercado, pero no para los casos en los que, por ejemplo ${ }^{30}$, se compra una entrada para asistir a un espectáculo, se llama a un «tele-taxi», se solicita una pizza por teléfono, en los que además el período que media entre la celebración del contrato y la prestación es muy corto. Recuérdese que con el derecho de desistimiento se persigue situar a las partes en la situación económica que ocuparían si el contrato no se hubiera celebrado. De ahí que el derecho no se reconozca para aquellos casos en los que los bienes puedan perder su valor de cambio o pasen definitivamente al patrimonio del consumidor, considerando además que en el caso de servicios, éstos no pueden ser «devueltos», una vez ejecutados completamente.

${ }_{29}$ Tal vez se huye de esta vía, que fue la seguida en parte en las CONCLUSIONES DE LA ABOGADO GENERAL SRA. CHRISTINE STIX-HACKL presentadas el 11 de noviembre de 2004, quien defendió en cambio que los contratos de alquiler no quedaban amparados por la expresión «servicios de transporte».

30 ARROYO, A., Los contratos a distancia, op. cit., pp. 210 y 211. 
La interpretación del Tribunal parece acorde con la finalidad de las excepciones al derecho de desistimiento de la Directiva 97/7/CE ${ }^{31}$, a pesar de que la resolución no sobresalga por su claridad en la exposición. Cuestión distinta es la de valorar si el derecho de desistimiento está sometido a más excepciones de las que debería y si parece razonable que en estos contratos de alquiler de vehículos, el empresario no haya de cumplir tampoco — como así es con la normativa vigente- con los deberes de información precontractual o de confirmación escrita de la información (cfr. en nuestro Derecho, art. 93.2. LGDCU). No ha de olvidarse, sin embargo, que la Directiva 97/7/CE es una Directiva de mínimos, lo que no impide la existencia de normativas nacionales más protectoras. En la práctica, la «política de cancelación» de muchas empresas es más protectora que la normativa comunitaria y nacional.

\section{Desistimiento de contrato por parte del consumidor y el alcance de la prohibición de repercutir sobre él de los gastos de envío: el Asunto Heinrich Heine}

A) Antecedentes: el litigio y la cuestión prejudicial. El Bundesgerichtshof (Tribunal Supremo) alemán promovió el 25 de noviembre de 2008 una cuestión de interpretación prejudicial ante el Tribunal de Luxemburgo, en un proceso iniciado por una asociación de consumidores y usuarios (Verbraucherzentrale Nordrhein-Westfalen e.V.) contra una empresa (Handelsgesellschaft Heinrich Heine GmbH). H. H. Heine es una sociedad especializada en la venta por correspondencia y en sus condiciones generales de venta se establece que el consumidor abonará 4,95 euros a tanto alzado en concepto de gastos de envío y que en caso de desistimiento, el proveedor no estará obligado a reembolsarle esta cantidad.

Los órganos jurisdiccionales de primera y segunda instancia estimaron la demanda de la asociación de consumidores y el Bundesgerichtshof decide plantear la cuestión prejudicial al considerar que el

\footnotetext{
31 En estos términos se expresaba la Abogada General en sus conclusiones, si bien terminó considerando que el contrato de alquiler no debía entenderse comprendido en la norma: «la excepción sectorial tiene por objeto proteger determinados servicios que funcionan mediante reservas y que se verían afectados de una forma inaceptable, ya que una reserva da lugar a una puesta a disposición de capacidades a las que ya no puede darse otro destino y que, en consecuencia, pueden entrañar unos costes de oportunidad elevados para los proveedores».
} 
Derecho alemán no confiere de manera explícita ${ }^{32}$ al consumidor ningún derecho de reembolso de los gastos de envío del pedido.

La pregunta que formuló el órgano judicial alemán es la siguiente: ¿Lo dispuesto en el artículo 6, apartados 1, segunda frase, y 2, de la Directiva 97/7/CE del Parlamento Europeo y del Consejo, de 20 de mayo de 1997, relativa a la protección de los consumidores en materia de contratos a distancia, debe ser interpretado en el sentido de que se opone a una normativa nacional con arreglo a la cual se podrán repercutir al consumidor los gastos de envío de las mercancías aunque éste haya desistido del contrato? El artículo 6.1 de la Directiva 97/7, después de reconocer al consumidor la posibilidad de desistir del contrato en un plazo mínimo de siete días laborables sin penalización alguna y sin indicación de los motivos, aclara que «el único gasto que podría imputarse al consumidor es el coste directo de la devolución de las mercancías al proveedor». Por su parte, el artículo 6.2 de dicha Directiva, también mencionado en el texto de la pregunta, dispone lo siguiente: «Cuando el consumidor haya ejercido el derecho de rescisión (léase "desistimiento") con arreglo a lo dispuesto en el presente artículo, el proveedor estará obligado a devolver las sumas abonadas por el consumidor sin retención de gastos. Únicamente podrá imputarse al consumidor que ejerza el derecho de rescisión el coste directo de la devolución de las mercancías. La devolución de las sumas abonadas deberá efectuarse lo antes posible y, en cualquier caso, en un plazo de treinta días».

B) La Sentencia de 15 de abril de 2010. El Bundesgerichtshof expuso varios argumentos que apoyaban la compatibilidad de la normativa alemana con la Directiva con base en: en primer lugar, sostiene que la expresión «infolge der Ausübung seines Widerrufsrechts» ("por el ejercicio de su derecho de desistimiento»), contenida en la versión alemana del artículo 6, apartado 1, párrafo primero, segunda frase y apartado 2, segunda frase, de la Directiva 97/7 (apoyada por las versiones inglesa y francesa) e insinúa que estas disposiciones sólo afectan a los gastos ocasionados por el ejercicio del derecho de desistimiento, con exclusión de los gastos de envío del bien que ya ha realizado en el momento del desistimiento. En segundo lugar, manifiesta que el artículo 6, apartado 2, primera frase, de dicha Directiva no excluye que, en caso de desistimiento, el proveedor obtenga una compensación por el valor de las prestaciones utilizadas por el con-

\footnotetext{
32 Los tribunales alemanes habían venido sosteniendo posiciones encontradas al respecto: vid., por un lado, OLG Nürnberg, Sentencia de 5.10.2004, Neue Juristische Wochenschrift - Rechtsprechungs-Report (NJW-RR) 2005, 15; y, por el otro, LG Karlsruhe, Sentencia de 19.12.2005, Multi-Media und Recht (MMR) 2006, 245.
} 
sumidor que, por su naturaleza, no pueden ser devueltas, siendo entonces compatible con dicho artículo considerar que el envío del bien es una prestación del proveedor por la que el consumidor debe restituir un valor de sustitución por el importe de los gastos de envío $\mathrm{y}$, consiguientemente, que la obligación de reembolso del proveedor se reduce en idéntica proporción. En tercer lugar, afirma que no existe certeza de que el objetivo de protección del consumidor expresado en particular en el decimocuarto considerando de la Directiva 97/7 exija el reembolso de los gastos de envío del bien. Como ilustración de este último argumento se pone como ejemplo el que en una compra ordinaria el consumidor soporta el coste del desplazamiento hasta el establecimiento comercial, sin contar el tiempo que ha tenido que dedicar a llegar hasta allí.

El Tribunal parte de la constatación de que la Directiva 97/7/CE no regula las consecuencias derivadas del ejercicio del derecho de desistimiento, como así es en efecto, ya que se deja a los Estados miembros determinar las «modalidades y condiciones» que correspondan (Cdo. $14^{\circ}$ Directiva). De ahí, que el Tribunal deba analizar entonces qué haya de entenderse por "sumas abonadas» — que han de ser reembolsadas al consumidor-, siendo así que concluye que no se deduce ni del tenor literal ni del sistema de la Directiva (interpretación gramatical y sistemática) que se trate «sólo del precio pagado por el consumidor» con exclusión de los gastos soportados por éste (§ 44).

Contiene el Tribunal interesantes manifestaciones acerca de las posibles disparidades lingüísticas de unas versiones $\mathrm{u}$ otras del texto comunitario ( $\S \S 49,50$ y sobre todo 51 ), que desembocan en una interpretación conforme a la estructura general y la finalidad de la normativa.

Así, se manifiesta que las disposiciones de la Directiva relativas a los efectos jurídicos del desistimiento tienen claramente por objetivo no desanimar al consumidor a ejercer ese derecho. Por tanto, sería contrario a dicho objetivo interpretar dichas disposiciones en el sentido de autorizar a los Estados miembros prever que los gastos de envío corran a cargo de dicho consumidor en el marco del ejercicio del derecho. Por otro lado, la imputación al consumidor de los gastos de envío además del coste de devolución de los bienes podría poner en cuestión un reparto equilibrado de los riesgos entre las partes en los contratos celebrados a distancia, al hacer que el consumidor cargara con el conjunto de los gastos vinculados al transporte de los bienes.

Finalmente, el Tribunal de Justicia declara que la Directiva se opone a una normativa nacional que permite al proveedor, en un 
contrato celebrado a distancia, imputar los gastos de envío de los bienes al consumidor en caso de que éste ejerza su derecho de rescisión.

C) Conclusiones. El Tribunal de Justicia considera que la Directiva se opone a imputar los gastos de envío de los bienes al consumidor. Y en este sentido ha de interpretarse nuestro ordenamiento, que ya venía disponiendo con claridad que el ejercicio del derecho de desistimiento no implicará gasto alguno (art. 73. LGDCU). Pero la Sentencia del Tribunal resulta tanto más interesante a los efectos de interpretar el artículo 76 LGDCU que se destina a la regulación de la devolución de sumas percibidas por el empresario, que es igualmente claro al disponer la devolución de «las sumas abonadas por el consumidor y usuario sin retención de gastos».

\section{El derecho de desistimiento como objeto de debate}

De las dos Sentencias del Tribunal de Justicia analizadas anteriormente puede apreciarse que el derecho de desistimiento, siendo el principal derecho atribuido al consumidor, es también el que más dudas suscita en cuanto a la regulación comunitaria y las correlativas nacionales.

De hecho, también se han planteado problemas respecto de la disminución del valor del bien, conforme al uso o la imposibilidad de devolver la prestación por parte del consumidor (cfr. arts. 74 y 75 LGDCU en cuanto a la regulación española). En el Asunto Messner ${ }^{33}$, el Tribunal entiende que la imposición general de una indemnización por el uso del bien adquirido mediante un contrato a distancia es incompatible con la Dir. 97/7/CE. Parece razonable considerar que si el consumidor pagase por el mero hecho de poder usar el bien mientras estuvo en su posesión, esto limitaría considerablemente el ejercicio del derecho de desistimiento, que sólo podría hacerse previo pago de la indemnización. Se atacaría de forma considerable la esencia del derecho como decisión libre, ejercitable ad nutum. Sin perjuicio de ello, el Tribunal matiza que nada se opone a que el consumidor pague por un uso que no sea conforme con la buena fe o cuando éste comporte un enriquecimiento sin causa, siempre que ello no menoscabe la finalidad de la Dir. 97/7/CE y, por tanto, siempre que no afecte a la eficacia del derecho de desistimiento. El juez nacional es quien debería en definitiva pronunciarse sobre estos extremos.

\footnotetext{
33 Sentencia 3 de septiembre de 2009: Asunto C-489/07.
} 


\section{BIBLIOGRAFÍA}

AAVV, Régimen Jurídico General del Comercio Minorista. Comentarios a la Ley 7/1996, de 15 de enero, de Ordenación del Comercio Minorista, y a la Ley Orgánica 2/1996, de 15 de enero, complementaria de la de Ordenación del Comercio Minorista, F. J. ALONSO ESPINOSA, J. A.; LÓPEZ PELLICER, J.; MASSAGUER FUENTES y A. REVERTE NAVARRO (coords.), McGraw-Hill, Madrid, 1999.

AAVV, El Sistema Arbitral de Consumo. Comentarios al Real Decreto 636/1993, de 3 de mayo (QUINTANA CARLO y BONET NAVARRO dirs.), Aranzadi, Pamplona, 1997.

AAVV, El Comercio Electrónico, J. A. ECHEBARRÍA SÁENZ (coord.), Edisofer, Madrid, 2001.

AAVV, Contratación y comercio electrónico (dir. ORDUÑA MORENO, F.; coord. CAMPUZANO LAGUILLO, A. B. y PLAZA PENADÉS, J.), Tirant lo Blanch, Valencia, 2003.

AAVV, Comercio Electrónico en Internet, J. A. GÓMEZ SEGADE (dir.), A. FERNÁNDEZ-ALBOR BALTAR y A. TATO PLAZA (coords.), Marcial Pons, Madrid, 2001.

AAVV, Comentarios a las Leyes de ordenación del comercio minorista, R. BERCOVITZ y J. LEGUINA (coords.), Tecnos, Madrid, 1997.

AAVV, Comentarios a la Ley de ordenación del comercio minorista y a la Ley Orgánica complementaria, J. L. PIÑAR MAÑAS y E. BELTRÁN SÁNCHEZ (dirs.), Universidad San Pablo CEU, Civitas, Madrid, 1997.

ADOBATI, E., «La Corte di Giustizia precisa la portata della protezione dei consumatori nei contratti a distanza di noleggio di autoveicoli conclusi via internet», Diritto comunitario e degli scambi internazionali 2005 pp. 705-706.

ARROYO APARICIO, A.: Los Contratos a distancia en la Ley de Ordenación del Comercio Minorista (Según la Ley 47/2002, de 19 diciembre 2002, de reforma de la Ley de Ordenación del Comercio Minorista). Aranzadi, Pamplona, 2003.

— «Contratos a distancia celebrados con consumidores según la Ley General para la Defensa de Consumidores y Usuarios (Texto Refundido por el Real Decreto Legislativo 1/2007)», Contratos Mercantiles, Tomo I, (Bercovitz, A. Dir.), Aranzadi, 2009, pp. 168 a 223.

- «Análisis crítico de la normativa relativa a la comercialización a distancia de servicios financieros destinados a los consumido- 
res», Tendencias actuales en torno al mercado del crédito, PULGAR, J. (Dir.), Marcial Pons, 2010, pp. 339 a 368.

BERCOVITZ, A. y BERCOVITZ, R.: Estudios jurídicos sobre protección de los consumidores. Tecnos, Madrid, 1987 (abreviadamente Estudios jurídicos).

BERCOVITZ RODRÍGUEZ-CANO, A.: «Ámbito de aplicación y derechos de los consumidores en la Ley General para la defensa de los consumidores y usuarios», Estudios jurídicos (BERCOVITZ, A. y BERCOVITZ, R.), cit., pp. 100 y ss.

- «Modalidades especiales de venta y protección de los consumidores», Estudios jurídicos (BERCOVITZ, A. y BERCOVITZ, R.), cit., pp. 159 y ss.

- «El Derecho comunitario europeo y las fuentes del Derecho español», Las fuentes efectivas del Derecho español tras la Constitución de 1978 (coord. Gemma FAJARDO), Centro de Alzira-Valencia de la Universidad Nacional de Educación a Distancia, 1992, pp. 11 a 44.

— «Nociones básicas sobre la protección de los consumidores en el ordenamiento jurídico español», en AAVV: Reforma del Derecho Privado y Protección del Consumidor, Valladolid, 1994, pp. 13 y ss.

- «Notas sobre los aspectos jurídico-mercantiles de la Ley de Ordenación del Comercio Minorista (LCM)», Estudios de Derecho mercantil. Homenaje al Profesor Justino F. Duque, vol. II, Universidad de Valladolid-Caja Duero. Valladolid, 1998, pp. 941 y ss.

- Apuntes de Derecho Mercantil, 10. ${ }^{a}$ ed., Aranzadi, Pamplona, 2009.

- «La protección de los consumidores en la Unión Europea», en Reglamentos y Directivas de la Unión Europea referentes a la Protección de los Consumidores, A. BERCOVITZ (dir.), Ministerio de Sanidad y Consumo. Madrid, 2002, pp. 17 a 36.

BERCOVITZ RODRÍGUEZ-CANO, R./CARRASCO PERERA, A.: «Borrador de Anteproyecto de ley de ventas por correo», EC, núm. 21, 1991, pp. 41 a 60.

CÁMARA LAPUENTE, S., «Tipos contractuales, excepciones sectoriales y metodología hermenéutica del derecho de consumo según la jurisprudencia comunitaria: "easyCar» o el desistimiento en el alquiler a distancia de vehículos (Sentencia TJCE de 10 de marzo de 2005, Asunto C-336/03)», RFDUG, 9/2006, pp. 375 a 405. 
CLEMENTE MEORO, M.: «El ejercicio del derecho de desistimiento en los contratos a distancia», Revista de Derecho Patrimonial, núm. 16, 2006, pp. 163-184.

GOYENS, M., «L'impact en droit belge de la future directive concernant la protection des consommateurs en matière de contrats négociés a distance», DCCR, núm. 30, 1996, pp. 7 a 28.

FUCHS, A., «Das Fernabsatzgesetz im neuen System des verbraucherschutzrechts», ZIP, 30/2000, pp. 1273 y ss.

IDOT, L.: «Précisions sur les exceptions à la directive sur les contrats à distance», Europe 2005 Mai Comm. n. ${ }^{\circ} 179$ p.27 y ss.

ILLESCAS ORTIZ, R.: Derecho de la contratación electrónica. 1. ${ }^{a}$ ed., Civitas. Madrid, 2001.

- «Claroscuro con patitos. De nuevo sobre la legislación proyectada en materia de contratación electrónica», RCE, núm. 27, 2002, pp. 3 a 26.

JUNKER, M., «Fernabsatzrecht und Online-Buchung von Mietwagen», Computer und Recht 2005 p.653-655.

JUSTE MENCÍA, J.: «Contratación a distancia y protección de los consumidores en el Derecho comunitario europeo. Algunas consideraciones sobre la Directiva 97/7/CE del Parlamento Europeo y del Consejo de 20 de mayo de 1997», Estudios de Derecho Mercantil. Homenaje al Profesor Justino Duque Domínguez, vol. II, Universidad de Valladolid-Caja Duero. Valladolid, 1998, pp. 1011 a 1034.

LOOS, M., «The case for a uniform and efficient right of withdrawal from consumer contracts in European Contract Law», Zeitschrift für Europäisches Privatrecht, 1/2007, pp. 5 a 36.

MADRID PARRA, A.: «Seguridad en el comercio electrónico», AAVV: Contratación y comercio electrónico, cit., pp. 123 a 193.

MIRANDA SERRANO, L. M.: «Derecho de desistimiento del consumidor en la contratación electrónica», en AA VV: Comercio electrónico y protección de los consumidores, G. A. BOTANA GARCÍA (coord.), Instituto Nacional del Consumo-La Ley. Madrid, 2001, pp. 575 y ss.

- Tratado de Derecho Mercantil. T. XXX: La contratación mercantil. Disposiciones generales. Protección de los consumidores, Madrid, 2006.

PASQUAU LIAÑO, M./GARCÍA GARNICA, C./ROBLES LATORRE, P./ESTEBAN DE LA ROSA, F.: «Propuesta de transposición al Derecho español de la Directiva 97/7/CE, de 20 de mayo de 1997, 
relativa a la protección de los consumidores en materia de contratos a distancia», EC, núm. 57, 2001, pp. 75 a 103.

PENDÓN MELÉNDEZ, M. A., «Reflexiones críticas acerca del régimen legal de las operaciones a distancia (en los contratos celebrados con consumidores y en las ventas entre empresarios) tras la entrada en vigor del Real Decreto Legislativo 1/2007, de 16 de noviembre», Derecho de los negocios, n. ${ }^{\circ} 209$ (febrero 2007), pp. 5 y ss.

PERALES VISCASILLAS, P.: «Formación del contrato», en AAVV: Comercio electrónico y protección de los consumidores, G. BOTANA GARCÍA (coord.), 1. ${ }^{\mathrm{a}}$ ed., Instituto Nacional del ConsumoLa Ley. Madrid, septiembre 2001, pp. 405 y ss.

- «Novedades sobre perfección del contrato», RCE, núm. 33, diciembre 2002, pp. 69 a 83.

REICH, N., "Die neue Richtlinie 97/7/EG über den Verbraucherschutz bei Vertragabschlüss im Fernabsatz», EuZW, 19/1997, pp. 581 a 589.

SÁNCHEZ GÓMEZ, A., en Comentario del Texto Refundido de la Ley General para la Defensa de los Consumidores y Usuarios, (R. Bercovitz, Coord.), Aranzadi, 2009, sub art. 92, pp. 1181 y ss.

TATO PLAZA, A.: «Aspectos jurídicos de la Publicidad y de las comunicaciones comerciales en internet», en AAVV: Comercio electrónico en Internet, cit., pp. 187 y ss.

TELKAMP, M., «Keine Kostenerstattung bei Widerruf von InternetAutomietverträgen», Ecolex 2005 p.584.

ULTSCH, M. L., "Widerrufbarkeit von Mietwagenbuchungen», Zeitschrift für europäisches Privatrecht, 2006 pp. 173-189.

WALDENBERGER, A., "Alles schwebend unwirksam -Distanzgeschäfte nach dem Referentenentwurf eines Fernabsatzgesetzes», $K \& R, 8 / 1999$, pp. 345 a 354.

WALTER, B. A., «Autovermietung und Fernabsatz: Der Ausgleich von Unternehmensinteressen und Verbraucherschutz», European Law Reporter, 2005 p. 203-205

ZARKA, J. C., "Contrats de locations de voitures conclus à distance et protection des consommateurs, La Semaine juridique - édition générale 2005 II, p. 10059.

ZUBIRI DE SALINAS, M., «La contratación electrónica como contratación a distancia», Revista Aragonesa de Administración Pública, núm. IV, 2001, pp. 193 a 235. 